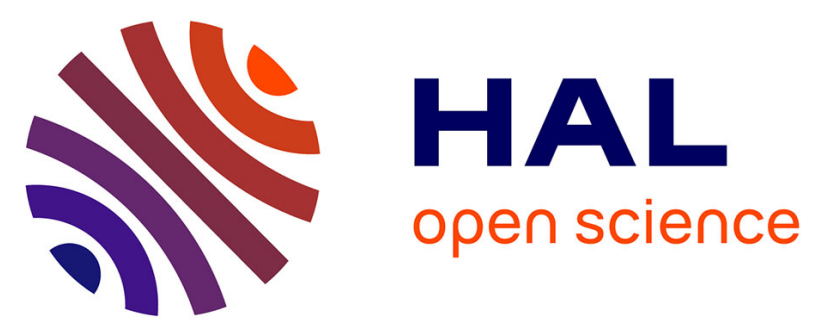

\title{
The relationship between peak warming and cumulative CO 2 emissions, and its use to quantify vulnerabilities in the carbon-climate-human system
}

Michael Raupach, Josep Canadell, Philippe Ciais, Pierre Friedlingstein, Peter Rayner, Catherine Trudinger

\section{- To cite this version:}

Michael Raupach, Josep Canadell, Philippe Ciais, Pierre Friedlingstein, Peter Rayner, et al.. The relationship between peak warming and cumulative $\mathrm{CO} 2$ emissions, and its use to quantify vulnerabilities in the carbon-climate-human system. Tellus B - Chemical and Physical Meteorology, 2011, 63 (2), pp.145-164. 10.1111/j.1600-0889.2010.00521.x . hal-02929059

\section{HAL Id: hal-02929059 \\ https://hal.science/hal-02929059}

Submitted on 29 Oct 2020

HAL is a multi-disciplinary open access archive for the deposit and dissemination of scientific research documents, whether they are published or not. The documents may come from teaching and research institutions in France or abroad, or from public or private research centers.
L'archive ouverte pluridisciplinaire HAL, est destinée au dépôt et à la diffusion de documents scientifiques de niveau recherche, publiés ou non, émanant des établissements d'enseignement et de recherche français ou étrangers, des laboratoires publics ou privés. 


\section{The relationship between peak warming and cumulative $\mathrm{CO}_{2}$ emissions, and its use to quantify vulnerabilities in the carbon-climate-human system}

Michael R. Raupach, Josep G. Canadell, Philippe Ciais, Pierre Friedlingstein, Peter J. Rayner \& Catherine M. Trudinger

To cite this article: Michael R. Raupach, Josep G. Canadell, Philippe Ciais, Pierre Friedlingstein, Peter J. Rayner \& Catherine M. Trudinger (2011) The relationship between peak warming and cumulative $\mathrm{CO}_{2}$ emissions, and its use to quantify vulnerabilities in the carbon-climatehuman system, Tellus B: Chemical and Physical Meteorology, 63:2, 145-164, DOI: 10.1111/ j.1600-0889.2010.00521.X

To link to this article: https://doi.org/10.1111/j.1600-0889.2010.00521.x

$$
\begin{aligned}
& \text { (c) } 2011 \text { The Author(s). Published by Taylor \& 冓 Published online: } 18 \text { Jan } 2017 . \\
& \text { Francis. }
\end{aligned}
$$

Submit your article to this journal $c \quad$ Џ Article views: 244 


\title{
The relationship between peak warming and cumulative $\mathrm{CO}_{2}$ emissions, and its use to quantify vulnerabilities in the carbon-climate-human system
}

\author{
By MICHAEL R. RAUPACH ${ }^{1,3 *}$, JOSEP G. CANADELL ${ }^{1,3}$, PHILIPPE CIAIS ${ }^{2,3}$, \\ PIERRE FRIEDLINGSTEIN ${ }^{2,3}$, PETER J. RAYNER ${ }^{2}$ and CATHERINE M. TRUDINGER ${ }^{4}$, \\ ${ }^{1}$ Centre for Atmospheric, Weather and Climate Research, CSIRO Marine and Atmospheric Research, \\ Canberra, ACT, Australia; ${ }^{2}$ LSCE/IPSL, Laboratoire CEA-CNRS-UVSQ, CEA de Saclay, Gif/Yvette, France; \\ ${ }^{3}$ ESSP Global Carbon Project, Canberra, Australia; ${ }^{4}$ Centre for Atmospheric, Weather and Climate Research, \\ CSIRO Marine and Atmospheric Research, Aspendale, Victoria, Australia
}

(Manuscript received 20 December 2009; in final form 22 November 2010)

\begin{abstract}
Interactions between the carbon cycle, climate and human societies are subject to several major vulnerabilities, broadly defined as factors contributing to the risk of harm from human-induced climate change. We assess five vulnerabilities: (1) effects of increasing $\mathrm{CO}_{2}$ on the partition of anthropogenic carbon between atmospheric, land and ocean reservoirs; (2) effects of climate change (quantified by temperature) on $\mathrm{CO}_{2}$ fluxes; (3) uncertainty in climate sensitivity; (4) non- $\mathrm{CO}_{2}$ radiative forcing and (5) anthropogenic $\mathrm{CO}_{2}$ emissions. Our analysis uses a physically based expression for $T_{\mathrm{p}}\left(Q_{\mathrm{p}}\right)$, the peak warming $T_{\mathrm{p}}$ associated with a cumulative anthropogenic $\mathrm{CO}_{2}$ emission $Q_{\mathrm{p}}$ to the time of peak warming. The approximations in this expression are evaluated using a non-linear box model of the carbon-climate system, forced with capped emissions trajectories described by an analytic form satisfying integral and smoothness constraints. The first four vulnerabilities appear as parameters that influence $T_{\mathrm{p}}\left(Q_{\mathrm{p}}\right)$, whereas the last appears through the independent variable. In terms of likely implications for $T_{\mathrm{p}}\left(Q_{\mathrm{p}}\right)$, the decreasing order of the first four vulnerabilities is: uncertainties in climate sensitivity, effects of non- $\mathrm{CO}_{2}$ radiative forcing, effects of climate change on $\mathrm{CO}_{2}$ fluxes and effects of increasing $\mathrm{CO}_{2}$ on the partition of anthropogenic carbon.
\end{abstract}

\section{Introduction}

The magnitude and rate of future human-induced climate change is uncertain because of multiple feedbacks in the earth system, many of which involve interactions between climate and the carbon cycle (Cox et al., 2000; Gruber et al., 2004; Steffen et al., 2004; IPCC, 2001b, 2007b). The implications of positive or reinforcing feedback processes are particularly significant because they lead to positively skewed probability distributions for future climate change (Roe and Baker, 2007; Knutti and Hegerl, 2008), which include non-negligible probabilities for extreme outcomes. Such a risk profile has prompted consideration of earth system 'vulnerability', a term which has been defined with different emphases in several disciplines. A definition for human-environment interactions in socio-ecological

\footnotetext{
* Corresponding author.

e-mail: michael.raupach@csiro.au

DOI: $10.1111 /$ j.1600-0889.2010.00521.x
}

systems (Turner et al., 2003) is: 'vulnerability is the degree to which a system, subsystem, or system component is likely to experience harm due to exposure to a hazard, either a perturbation or stress/stressor". With an emphasis on climate change, the Intergovernmental Panel on Climate Change (IPCC) defined vulnerability as 'the degree to which a system is susceptible to, or unable to cope with, adverse effects of climate change, including climate variability and extremes' (IPCC, 2007a, p883, p783; also IPCC, 2001a, p. 995).

The term 'vulnerability' has also been applied to carbonclimate interactions in a narrower sense, to mean the extent to which the build-up of atmospheric $\mathrm{CO}_{2}$ from anthropogenic emissions may be accelerated by climate change itself through positive carbon-climate feedbacks. Two broad groups of processes are involved, those affecting the natural land and ocean sinks of atmospheric $\mathrm{CO}_{2}$, and those leading to $\mathrm{CO}_{2}$ releases from previously immobile stores of carbon on land or in the ocean. The consequences of both groups were investigated by Gruber et al. (2004) using a heuristic, risk-based approach. More 
quantitatively, carbon-climate model intercomparison experiments (Friedlingstein et al., 2006; Sitch et al., 2008) indicate significant enhancement of climate change by climate-induced effects on land and ocean $\mathrm{CO}_{2}$ sinks, but with substantial variability between models, especially for the land sink. A number of studies have also addressed specific carbon pools which are vulnerable to disturbance by climate change and/or land use change, such as organic carbon in frozen soils (Zimov et al., 2006; Schuur et al., 2008; Tarnocai et al., 2009) and in tropical peatlands (Hooijer et al., 2009).

In this work we define vulnerabilities broadly, as factors contributing to the risk of harm from human-induced climate change. These factors include both forcings and responses. The definition of 'harmful' or 'dangerous' climate change is necessarily subjective, involving value judgements about the well being of humankind and the biosphere. One widely used marker is a peak warming of $2 \mathrm{~K}$ above pre-industrial temperatures (Schellnhuber et al., 2006). For any nominated marker, the risk of crossing that point can be estimated objectively as a function of the magnitude of anthropogenic forcing on climate and biogeochemical cycles, the biophysical response of the system for a given forcing (the system sensitivity) and uncertainty in both forcing and response.

Our aim is to quantify and rank five vulnerabilities in the carbon-climate-human system, arising from (1) effects of increasing $\mathrm{CO}_{2}$ on the partition of anthropogenic carbon between atmospheric, land and ocean reservoirs; (2) effects of climate change (quantified by temperature) on $\mathrm{CO}_{2}$ fluxes, including releases of carbon from previously undisturbed pools; (3) climate sensitivity; (4) changes in non- $\mathrm{CO}_{2}$ radiative forcing and (5) anthropogenic $\mathrm{CO}_{2}$ emissions. Of these five, the last two are human forcings and the first three involve biophysical responses. These five vulnerabilities are intercompared by examining their relative effects on peak global temperature $\left(T_{\mathrm{p}}\right)$ relative to pre-industrial temperatures, used as a single measure of system response.

The analysis is based on two models for carbon-climate interactions: (1) a new algebraic expression for the peak warming $T_{\mathrm{p}}$ associated with a cumulative total anthropogenic $\mathrm{CO}_{2}$ emission $Q_{\mathrm{p}}[\mathrm{PgC}]$ to the time of peak warming, and (2) a non-linear box model for global $\mathrm{CO}_{2}$, other greenhouse gases and global temperature, using established formulations. Model 1 is an analytic counterpart of recent model results (Allen et al., 2009; Matthews et al., 2009; Meinshausen et al., 2009; Zickfeld et al., 2009) which found that $T_{\mathrm{p}}$ (induced by $\mathrm{CO}_{2}$ forcing) is a function of $Q_{\mathrm{p}}$ with a definable uncertainty range. Model 1 yields an approximate algebraic expression for $T_{\mathrm{p}}\left(Q_{\mathrm{p}}\right)$ which is useful for two reasons: its structure provides some insight into the ways that vulnerabilities interact, and it is easily amenable to perturbation analysis to quantify and rank uncertainties and their implications for vulnerability. Model 2 is used to further explore the robustness of the relationship between $T_{\mathrm{p}}$ and $Q_{\mathrm{p}}$, and to evaluate the approximations in model 1.

\section{Models}

\subsection{Algebraic expression for peak warming}

Global temperature can be related to radiative forcing by a climate response function, which represents the dynamics of a complex climate model in a low-dimensional representation ( $\mathrm{Li}$ and Jarvis, 2009; Li et al., 2009). In this representation, a trajectory $R(t)$ of radiative forcing [ $\mathrm{W} \mathrm{m}^{-2}$ ] leads to a global temperature perturbation (from a mean pre-industrial state) given by

$T(t)=\lambda_{\mathrm{q}} \int_{0}^{t} R^{\prime}(\tau) h_{\mathrm{T}}(t-\tau) \mathrm{d} \tau$,

where $h_{\mathrm{T}}(t)$ is the climate response function (the fractional response to a unit step in radiative forcing), $t$ is time from the start of the industrial era, $R^{\prime}(t)=\mathrm{d} R(t) / \mathrm{d} t$, and $\lambda_{\mathrm{q}}\left[\mathrm{K} \mathrm{W}^{-1} \mathrm{~m}^{2}\right]$ is the equilibrium climate sensitivity. ${ }^{1}$ By definition, $\lambda_{\mathrm{q}}$ satisfies

$T_{\mathrm{q}}=\lambda_{\mathrm{q}} R_{\mathrm{q}}$,

where $T_{\mathrm{q}}$ is the long-term equilibrium warming in response to a steady radiative forcing $R_{\mathrm{q}}$.

We are concerned here not with the equilibrium response to steady forcing, but with the transient temperature response $T(t)$ to a forcing trajectory involving a finite cumulative emission of $\mathrm{CO}_{2}$. This yields a temperature trajectory with a peak at some time $t_{\mathrm{p}}$, followed by a slow decrease. The peak warming can be characterized by a peak climate sensitivity $\lambda_{\mathrm{p}}$, such that

$T_{\mathrm{p}}=\lambda_{\mathrm{p}} R_{\mathrm{p}}$,

where $T_{\mathrm{p}}=T\left(t_{\mathrm{p}}\right)$ is the peak warming and $R_{\mathrm{p}}=R\left(t_{\mathrm{p}}\right)$ is the radiative forcing at the time of peak warming. The peak sensitivity $\lambda_{\mathrm{p}}$ is akin to, but not the same as, the transient climate sensitivity ( $T$ at the time of $\mathrm{CO}_{2}$ doubling for a $1 \% \mathrm{y}^{-1} \mathrm{CO}_{2}$ increase; IPCC, 2001b).

The radiative forcing is approximately the sum of contributions from $\mathrm{CO}_{2}$, non- $\mathrm{CO}_{2}$ greenhouse gases $\left(\mathrm{CH}_{4}, \mathrm{~N}_{2} \mathrm{O}\right.$, halocarbons and others) and non-gaseous agents (aerosols, albedo changes, volcanic effects and others). Writing the $\mathrm{CO}_{2}$ forcing as $R_{\mathrm{C}}$ and lumping all other gaseous and non-gaseous forcings into a total non- $\mathrm{CO}_{2}$ forcing $R_{\mathrm{N}}$, we have

$R(t)=R_{\mathrm{C}}(t)+R_{\mathrm{N}}(t)$.

The $\mathrm{CO}_{2}$ contribution to radiative forcing is taken to be (IPCC, 2001b, p. 358):

$R_{\mathrm{C}}(t)=5.35 \ln \left(\frac{C_{\mathrm{A}}(t)}{C_{\mathrm{A} 0}}\right)$,

where $C_{\mathrm{A}}(t)$ is the mass of $\mathrm{CO}_{2}$ in the atmosphere (equal to $2.13\left[\mathrm{CO}_{2}\right](t)$, with $C_{\mathrm{A}}$ in $\mathrm{PgC},\left[\mathrm{CO}_{2}\right]$ the concentration in

\footnotetext{
${ }^{1}$ Climate sensitivity in units of $\mathrm{K}$ per $\mathrm{CO}_{2}$ doubling is related to the unit used here by $\lambda_{\mathrm{q}}\left[\mathrm{K}\left(2 \times \mathrm{CO}_{2}\right)^{-1}\right]=3.71 \lambda_{\mathrm{q}}\left[\mathrm{K} \mathrm{W}^{-1} \mathrm{~m}^{2}\right]$, where $3.71 \mathrm{~W} \mathrm{~m}^{-2}$ is the assumed radiative forcing for $\mathrm{CO}_{2}$ doubling (Myhre et al., 1998).
} 
ppm and $2.13 \mathrm{PgC} \mathrm{ppm}^{-1}$ a conversion factor); and $C_{\mathrm{A} 0}=$ $2.13\left[\mathrm{CO}_{2}\right]_{0}$ the pre-industrial mass of atmospheric $\mathrm{CO}_{2}$, with $\left[\mathrm{CO}_{2}\right]_{0} \approx 280 \mathrm{ppm}$ the pre-industrial $\mathrm{CO}_{2}$ concentration. A subscript 0 denotes the pre-industrial equilibrium value of any quantity.

We express the increase in atmospheric $\mathrm{CO}_{2}$ since preindustrial times $\left(C_{\mathrm{A}}-C_{\mathrm{A} 0}\right.$, in $\left.\mathrm{PgC}\right)$ as the result of three influences: (1) anthropogenic emissions, (2) the effects of increasing $\mathrm{CO}_{2}$ on the partition of anthropogenic carbon between atmospheric, land and ocean reservoirs and (3) the effects of climate change (quantified by temperature) on the carbon cycle, including both currently active $\mathrm{CO}_{2}$ fluxes and releases of carbon from previously undisturbed pools. The added atmospheric $\mathrm{CO}_{2}$ concentration from the first two influences is $A(t) Q(t)$, where $Q(t)$ is the total cumulative anthropogenic $\mathrm{CO}_{2}$ emission from pre-industrial times to time $t$, and $A(t)$ is the cumulative airborne fraction (CAF) of $\mathrm{CO}_{2}$ in the absence of climate (temperature) feedback on the carbon cycle. The cumulative emission $Q(t)$ is the time integral of the total emission flux $(F(t))$ from fossil fuels and other industrial processes including cement production (collectively denoted $F_{\text {Foss }}(t)$ ) and from net land use change $\left(F_{\mathrm{LUC}}(t)\right)$. The CAF is the fraction of total cumulative emissions remaining in the atmosphere, $\left(C_{\mathrm{A}}(t)-C_{\mathrm{A} 0}\right) / Q(t)$. This accounts for time-integrated effects of land and ocean $\mathrm{CO}_{2}$ sinks, which have together removed more than half of all cumulative emissions through the industrial era to date. The observed cumulative AF was 0.42 in 2009 (Canadell et al., 2007; Le Quere et al., 2009). This observed quantity is slightly different from the quantity $A(t)$ used in this analysis, which is the CAF without carbon-climate (temperature) feedbacks.

The added $\mathrm{CO}_{2}$ concentration from the third influence (effect of climate change on the carbon cycle) is expressed as $\gamma T(t)$, where $\gamma\left[\mathrm{PgC} \mathrm{K}^{-1}\right]$ is the aggregate sensitivity of all land and ocean carbon pools to climate change, including both currently mobile pools (such as soil carbon) and pools which are currently largely immobile but vulnerable to disturbance under climate change (such as carbon in frozen soils). Climate change is parameterized by the single variable $T(t)$, recognizing that release of $\mathrm{CO}_{2}$ from carbon pools through climate change involves multiple processes which respond not only through warming but also through other physical variables such as precipitation and radiation.

Combining the contributions from all three influences, we have

$C_{\mathrm{A}}(t)-C_{\mathrm{A} 0}=A(t) Q(t)-\gamma T(t)$.

Taking $t$ to be the time $t_{\mathrm{p}}$ of peak warming, eqs. (3)-(6) yield

$T_{\mathrm{p}}=\lambda_{\mathrm{p}}\left[5.35 \ln \left(1+\frac{A_{\mathrm{p}} Q_{\mathrm{p}}+\gamma T_{\mathrm{p}}}{C_{A 0}}\right)+R_{\mathrm{Np}}\right]$,

where $A_{\mathrm{p}}, Q_{\mathrm{p}}, T_{\mathrm{p}}$ and $R_{\mathrm{Np}}$ are the values of $A(t), Q(t), T(t)$ and $R_{\mathrm{N}}(t)$ at $t=t_{\mathrm{p}}$. We now solve for $T_{\mathrm{p}}$ by using the approximation $\ln (x+h) \approx \ln (x)+h / x$, taking $x=1+A_{\mathrm{p}} Q_{\mathrm{p}} / C_{\mathrm{A} 0}=C_{\mathrm{A}}\left(t_{\mathrm{p}}\right) / C_{\mathrm{A} 0}$ and $h=\gamma T_{\mathrm{p}} / C_{\mathrm{A} 0}$. The approximation error is of order $h^{2}$ and is less than $1 \%$ with reference parameters defined later. The result is

$T_{\mathrm{p}} \approx \frac{\lambda_{\mathrm{p}}}{1-g}\left[5.35 \ln \left(1+\frac{A_{\mathrm{p}} Q_{\mathrm{p}}}{C_{\mathrm{A} 0}}\right)+R_{\mathrm{Np}}\right]$

with $g=\frac{5.35 \lambda_{\mathrm{p}} \gamma}{C_{\mathrm{A} 0}+A_{\mathrm{p}} Q_{\mathrm{p}}}$.

The factor $1 /(1-g)$ is the amplification of peak warming by effects of warming on $\mathrm{CO}_{2}$ fluxes, including both currently active fluxes and releases of carbon from previously undisturbed pools. This form is generically familiar as the amplification arising when a fraction $g$ of the output of a system, the 'gain', is added to the system input (Roe and Baker, 2007).

Equation (8) is our algebraic expression for peak warming as a function of forcings $\left(Q_{\mathrm{p}}\right.$ and $\left.R_{\mathrm{Np}}\right)$ and properties of the carbon-climate system $\left(T_{\mathrm{p}}, A_{\mathrm{p}}\right.$ and $\left.\gamma\right)$, all at the time of peak warming, $t_{\mathrm{p}}$. Because of the dominant role of $\mathrm{CO}_{2}$ forcing we often denote this expression as $T_{\mathrm{p}}\left(Q_{\mathrm{p}}\right)$, with other dependencies understood. The parameters in eq. (8) correspond to the five sources of vulnerability outlined in the introduction: (1) effects of $\mathrm{CO}_{2}$ on the partition of anthropogenic carbon are quantified by $A_{\mathrm{p}}$, (2) effects of climate (temperature) change on the carbon cycle by $\gamma$, (3) climate sensitivity by $\lambda_{\mathrm{p}}$, (4) non- $\mathrm{CO}_{2}$ radiative forcing by $R_{\mathrm{Np}}$ and (5) $\mathrm{CO}_{2}$ forcing by $Q_{\mathrm{p}}$.

Given the definitions of its parameters, eq. (8) is formally exact apart from a linearization with a small error (typically less than $1 \%$ ). The utility of eq. (8) therefore depends mainly on the robustness with which its parameters can be estimated. In particular, the parameters $\lambda_{\mathrm{p}}$ and $A_{\mathrm{p}}$ are pathdependent properties of carbon-climate trajectories. The extent and consequences of this path dependency are investigated later.

\subsection{Non-linear box model}

To investigate the robustness of the relationship $T_{\mathrm{p}}\left(Q_{\mathrm{p}}\right)$, and also the properties of parameters in eq. (8), we use a non-linear model for global $\mathrm{CO}_{2}$, other greenhouse gases and global temperature. This is a globally averaged or 'box' model of the carbon-climate system (Oeschger et al., 1975; Joos et al., 1996 and many others), using well-established formulations. Equations and parameters are given in Appendix A and Tables A1 and A2. The model includes non-linearities in the response of terrestrial carbon assimilation to $\mathrm{CO}_{2}$, the buffering of $\mathrm{CO}_{2}$ in the ocean mixed layer, temperature responses of land-air and ocean-air $\mathrm{CO}_{2}$ exchanges and the response of radiative forcing to gas concentrations.

Model state variables are carbon masses in the atmosphere, in fast and slow terrestrial biospheric $\mathrm{C}$ pools, and in a set of ocean $\mathrm{C}$ pools; the atmospheric concentrations of $\mathrm{CH}_{4}, \mathrm{~N}_{2} \mathrm{O}$ and halocarbons (represented here only by CFC-11 and CFC12); and global perturbation temperature components. Forcing 
is by specified trajectories for $\mathrm{CO}_{2}, \mathrm{CH}_{4}, \mathrm{~N}_{2} \mathrm{O}$ and halocarbon emissions, which in turn yield concentrations, radiative forcing and global temperature. Radiative forcing occurs from $\mathrm{CO}_{2}, \mathrm{CH}_{4}, \mathrm{~N}_{2} \mathrm{O}$, halocarbons and aerosols. The negative radiative forcing contribution from aerosols is taken to be proportional to total $\mathrm{CO}_{2}$ emissions (on the assumptions that anthropogenic aerosol inputs are approximately proportional to total $\mathrm{CO}_{2}$ emissions and removals are rapid), with a proportionality coefficient set to match total radiative forcing in 2005 (Appendix A). Because some non- $\mathrm{CO}_{2}$ anthropogenic radiative forcings are omitted, the resulting modelled aerosol forcing is likely to underestimate the actual negative aerosol forcing in 2005.

Past emissions trajectories for $\mathrm{CO}_{2}$ are set from data, and future trajectories are described in the next subsection. For $\mathrm{CH}_{4}$, $\mathrm{N}_{2} \mathrm{O}$ and halocarbons, past emissions are set from data and the requirement that the model match observed concentrations, and future emissions are assumed to follow the IPCC SRES (Special Report on Emissions Scenarios) A1B marker scenario (Nakicenovic et al., 2000). Temperature is related to radiative forcing by eq. (1), using a climate response function of the common form of a sum of decaying exponentials in time (Appendix B) and solved as a set of linear equations (Appendix A). We use a three-term climate response function (Table A2) for the HadCM3 climate model (Li and Jarvis, 2009) with its associated climate sensitivity, $\lambda_{\mathrm{q}}=1.235 \mathrm{~K} \mathrm{~W}^{-1} \mathrm{~m}^{2}$.

Model parameters were selected for consistency with past data, accounting for prior constraints (see Table A2 for values). The temperature part of the model is parameterized entirely by the three-term HadCM3 climate response function and its equilibrium climate sensitivity.

The value $\lambda_{\mathrm{q}}=1.235 \mathrm{~K} \mathrm{~W}^{-1} \mathrm{~m}^{2}$ for the equilibrium climate sensitivity from the HadCM3 model is significantly higher than many recent estimates, which are typically $3(2$ to 4.5$) \mathrm{K}(2 \times$ $\left.\mathrm{CO}_{2}\right)^{-1}$ or $0.81(0.54$ to 1.21$) \mathrm{K} \mathrm{W}^{-1} \mathrm{~m}^{2}$ (IPCC, 2007b, p. 66; also see Meinshausen, 2006; Knutti and Hegerl, 2008). The wide and positively skewed uncertainty in the equilibrium climate sensitivity reflects both uncertainty and asymmetry in the effects of climate feedbacks, for instance through water vapour, clouds and aerosols (Roe and Baker, 2007; Knutti and Hegerl, 2008). The value $\lambda_{\mathrm{q}}=1.235 \mathrm{~K} \mathrm{~W}^{-1} \mathrm{~m}^{2}$ is high because the longest time scale in the three-term HadCM3 climate response function (Li and Jarvis, 2009) is nearly 1500 years, long enough to include slow feedbacks such as ocean and cryosphere responses which are often not included in determinations of climate sensitivity but which contribute to the full 'earth system' sensitivity (Hansen et al., 2008). There is an association between the longterm equilibrium sensitivity and the long time scales of a climate or earth system model, although transient responses are better constrained by observed temperature trends (Frame et al., 2006). The uncertainty in equilibrium climate or earth system sensitivity arises mainly from uncertainty about slow feedbacks and responses.

\section{3. $\mathrm{CO}_{2}$ emissions trajectories}

The $\mathrm{CO}_{2}$ emission flux $\left[\mathrm{PgC}^{-1}\right]$ from fossil fuels and other industrial processes is specified with an emissions trajectory defined by

$$
\begin{aligned}
F_{\mathrm{Foss}}(t) & = \begin{cases}\text { observations } & \left(t \leq t_{1}\right), \\
F_{\mathrm{m}} \exp \left(r\left(t-t_{\mathrm{m}}\right)\right) & \left(t_{1}<t \leq t_{\mathrm{m}}\right), \\
f(t) & \left(t>t_{\mathrm{m}}\right),\end{cases} \\
f(t) & =F_{\mathrm{m}}\left[1+(r+m)\left(t-t_{\mathrm{m}}\right)\right] \exp \left(-m\left(t-t_{\mathrm{m}}\right)\right) .
\end{aligned}
$$

Here $t_{1}$ is the time to which observations are available, $t_{\mathrm{m}}$ is the time in the future at which mitigation begins, $F_{\mathrm{m}}$ is the emission at time $t_{\mathrm{m}}, r\left[\mathrm{y}^{-1}\right]$ is the proportional growth rate of $F_{\text {Foss }}(t)$ before mitigation, and $m\left[\mathrm{y}^{-1}\right]$ is an applied mitigation rate. This 'smooth capped' emissions trajectory merges an exponential growth phase with growth rate $r$, applicable for $t \leq t_{\mathrm{m}}$, with a mitigation phase starting at $t=t_{\mathrm{m}}$ in which emissions follow the trajectory $f(t)$, initially increasing at growth rate $r$ and ultimately decreasing exponentially at the mitigation rate $m$. Emissions reach their maximum after $t=t_{\mathrm{m}}$ because initial growth must be overcome.

The all-time cumulative emission $[\mathrm{PgC}]$ is the finite quantity

$$
\begin{aligned}
Q_{\mathrm{Foss}}(\infty)= & \int_{t_{0}}^{\infty} F_{\mathrm{Foss}}(t) \mathrm{d} t \\
= & Q_{\text {Foss }}\left(t_{1}\right)+\frac{F_{\mathrm{m}}}{r}\left[1-\exp \left(r\left(t-t_{\mathrm{m}}\right)\right)\right] \\
& +\frac{F_{\mathrm{m}}(2 m+r)}{m^{2}}
\end{aligned}
$$

where the three terms on the right-hand side are respectively the contributions to the integral from the past $\left(t \leq t_{1}\right)$, future pre-mitigation $\left(t_{1}<t \leq t_{\mathrm{m}}\right)$ and mitigation $\left(t>t_{\mathrm{m}}\right)$ phases of eq. (9). The initial time $\left(t_{0}\right)$ is taken as 1751 .

Using data from sources given in Appendix C, cumulative fossil-fuel emissions from 1751 to the end of 2008 (denoted as $\left.t_{1}=2008.99\right)$ were $Q_{\text {Foss }}\left(t_{1}\right)=346 \mathrm{PgC}$, and $F_{\text {Foss }}$ in 2008 was $8.67 \mathrm{PgC} \mathrm{y}^{-1}$. The growth rate of $F_{\text {Foss }}$ for the decade 2000.00-2009.99 was $r=0.03 \mathrm{y}^{-1}$, a value which includes an estimate of the effect of the recent global financial crisis (Le Quere et al., 2009; Raupach and Canadell, 2010).

In this work, net $\mathrm{CO}_{2}$ emissions from land use change $\left(F_{\text {LUC }}(t)\right)$ are specified simply by past emissions to time $t_{1}=$ 2008.99 (Houghton, 2003; Le Quere et al., 2009) and a linear decrease in the future to zero at $t=2100$. Cumulative net $\mathrm{CO}_{2}$ emissions from land use change were $160 \mathrm{PgC}$ from 1850 to the end of 2008. To estimate cumulative land use change emissions before 1850 , we assume a linear increase from zero in 1751 to $0.5 \mathrm{PgC} \mathrm{y}^{-1}$ for 1850 , the earliest available estimate (Houghton, 2003). This implies an additional $25 \mathrm{PgC}$ of cumulative emission before 1850. The resulting cumulative land use change emission from 1751 onwards is $Q_{\mathrm{LuC}}(t)=185 \mathrm{PgC}$ to $t_{1}=2008.99$. 


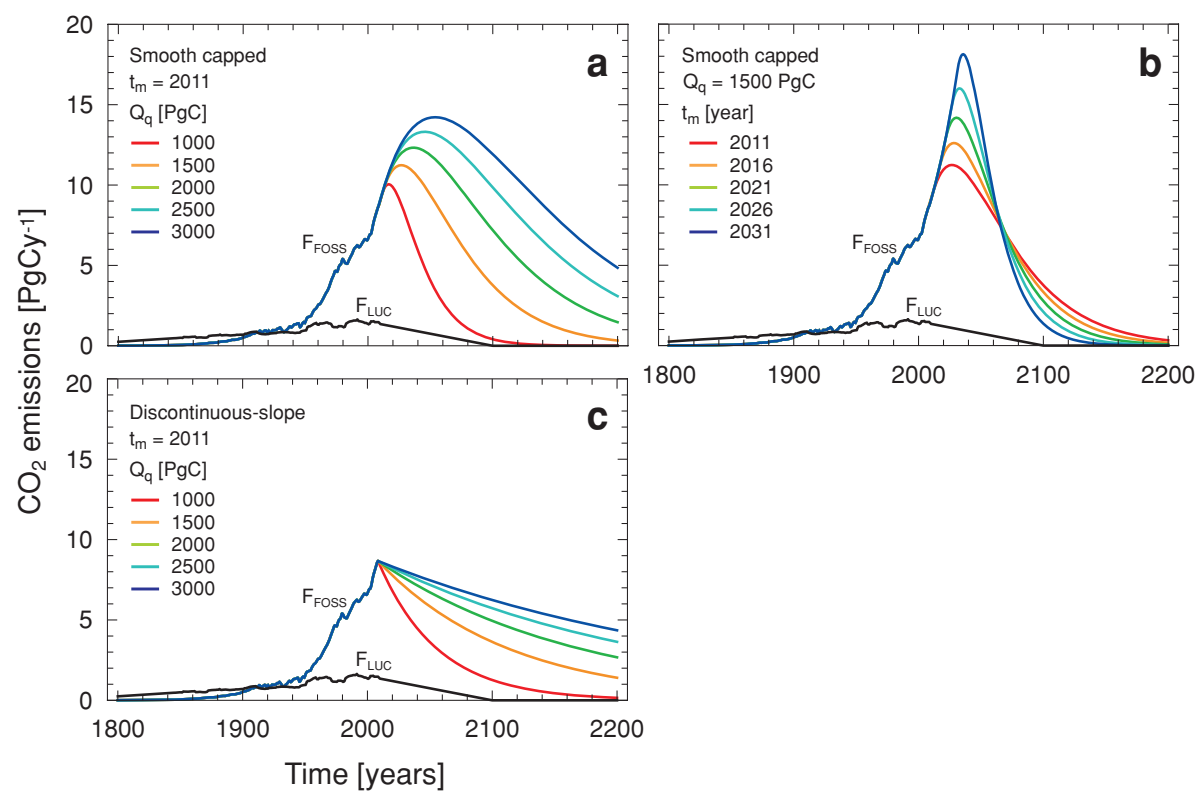

Fig. 1. Capped trajectories for $\mathrm{CO}_{2}$ emissions from fossil fuels and other industrial sources ( $F_{\mathrm{Foss}}$, colours), and emissions from land use change ( $F_{\text {LUC }}$, black). Total ( $F_{\text {Foss }}+F_{\text {LUC }}$ ) emissions integrate over all time to indicated quotas $Q_{\mathrm{q}}$ from 1000 to $3000 \mathrm{PgC}$. (a) Smooth capped trajectories for $F_{\text {Foss }}$ from eq. (9), with $Q_{\mathrm{q}}$ varying from 1000 to $3000 \mathrm{PgC}$ and mitigation start time $t_{\mathrm{m}}=2011$. (b) As for (a), with $t_{\mathrm{m}}$ varying from 2011 to 2031 and $Q_{\mathrm{q}}=1500 \mathrm{PgC}$. (c) Discontinuous-slope capped trajectories from eq. (12), with $Q_{\mathrm{q}}$ varying from 1000 to $3000 \mathrm{PgC}$ and $t_{\mathrm{m}}=$ 2011. In all panels, growth rate in $F_{\text {Foss }}$ at time $t_{\mathrm{m}}$ is $r=0.03 \mathrm{y}^{-1}$.

Figures $1 \mathrm{a}$ and $\mathrm{b}$ show capped trajectories for $\mathrm{CO}_{2}$ emissions from fossil fuels $\left(F_{\text {Foss }}(t)\right)$ from eq. (9), together with net land use change $\left(F_{\text {LUC }}(t)\right)$ specified as above. In these trajectories, there is a specified cap

$Q_{\mathrm{q}}=Q_{\mathrm{Foss}}(\infty)+Q_{\mathrm{LUC}}(\infty)$

for the all-time total cumulative $\mathrm{CO}_{2}$ emission from both fossil fuels and land use change, from 1751 to the far future. In Fig. $1 \mathrm{a}, Q_{\mathrm{q}}$ varies among curves with a fixed mitigation start time $t_{\mathrm{m}}$ in eq. (9), whereas in Fig. $1 \mathrm{~b}, t_{\mathrm{m}}$ varies among curves with fixed $Q_{\mathrm{q}}$. As $Q_{\mathrm{q}}$ increases with fixed $t_{\mathrm{m}}$, peak emissions occur progressively later and the subsequent decay rate decreases (Fig. 1a). As the start of mitigation $\left(t_{\mathrm{m}}\right)$ is delayed with a given cap $Q_{\mathrm{q}}$, peak emissions occur later but the subsequent decay rate increases sharply (Fig. 1b).

We can write $Q_{\mathrm{q}}$ as a sum of four components:

$$
\begin{aligned}
Q_{\mathrm{q}}= & \text { past } Q_{\mathrm{Foss}}+\text { future } Q_{\mathrm{Foss}} \\
& + \text { past } Q_{\mathrm{LUC}}+\text { future } Q_{\mathrm{LUC}} .
\end{aligned}
$$

From the above data, past $Q_{\text {Foss }}=346( \pm 50) \mathrm{PgC}$ and past $Q_{\mathrm{LUC}}=185( \pm 70) \mathrm{PgC}$, taking the past-future divide as $t_{1}=$ 2008.99 and showing heuristic uncertainty estimates in brackets. Under the above assumed trajectory for future $F_{\text {LUC }}(t)$, we have future $Q_{\mathrm{LUC}}=70( \pm 50) \mathrm{PgC}$. (Although future land use change emissions are subject to human management like fossil fuel emissions, future $Q_{\mathrm{LUC}}$ is likely to be much smaller than future $Q_{\text {Foss }}$ and is prescribed here for simplicity). The sum of

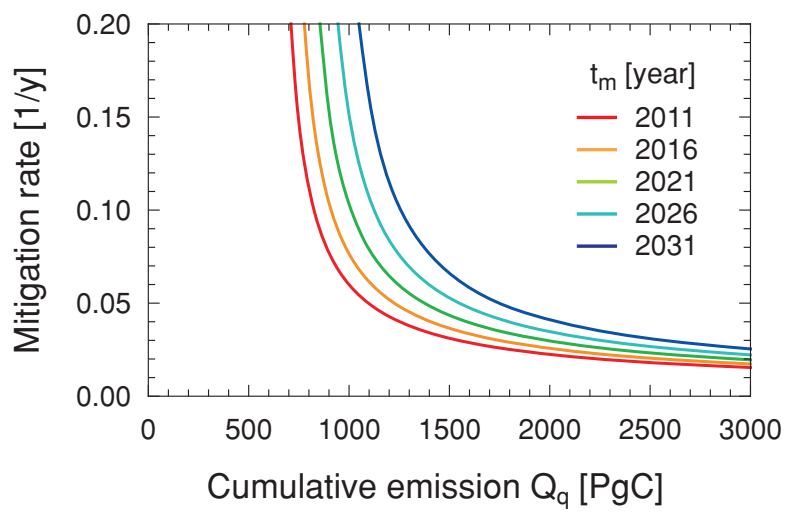

Fig. 2. Mitigation rate $m$ as a function of all-time cumulative emission $Q_{\mathrm{q}}$, for smooth capped emissions trajectories (eq. 9) with $r=0.03 \mathrm{y}^{-1}$ and with mitigation start time $t_{\mathrm{m}}$ varying from 2011 to 2031. Colours correspond with Fig. 1b, which shows trajectories for $F_{\text {Foss }}(t)$ with the same values of $t_{\mathrm{m}}$ at $Q_{\mathrm{q}}=1500 \mathrm{PgC}$. Components of $Q_{\mathrm{q}}$ other than $F_{\text {Foss }}$ are specified by eq. (11) and following text.

past $Q_{\text {Foss }}$, past $Q_{\mathrm{LUC}}$ and future $Q_{\mathrm{LUC}}$ yields a total commitment apart from future $Q_{\text {Foss }}$ of $600( \pm 100) \mathrm{PgC}$ to nearest $10 \mathrm{PgC}$, with root-mean-square summation of uncertainties. The future quota for $Q_{\text {Foss }}$ is less than any nominated value of $Q_{\mathrm{q}}$ by this amount.

Figure 2 shows the mitigation rate $m$ required to achieve a given $Q_{\mathrm{q}}$, for five mitigation start times $t_{\mathrm{m}}$ between 2011 and 

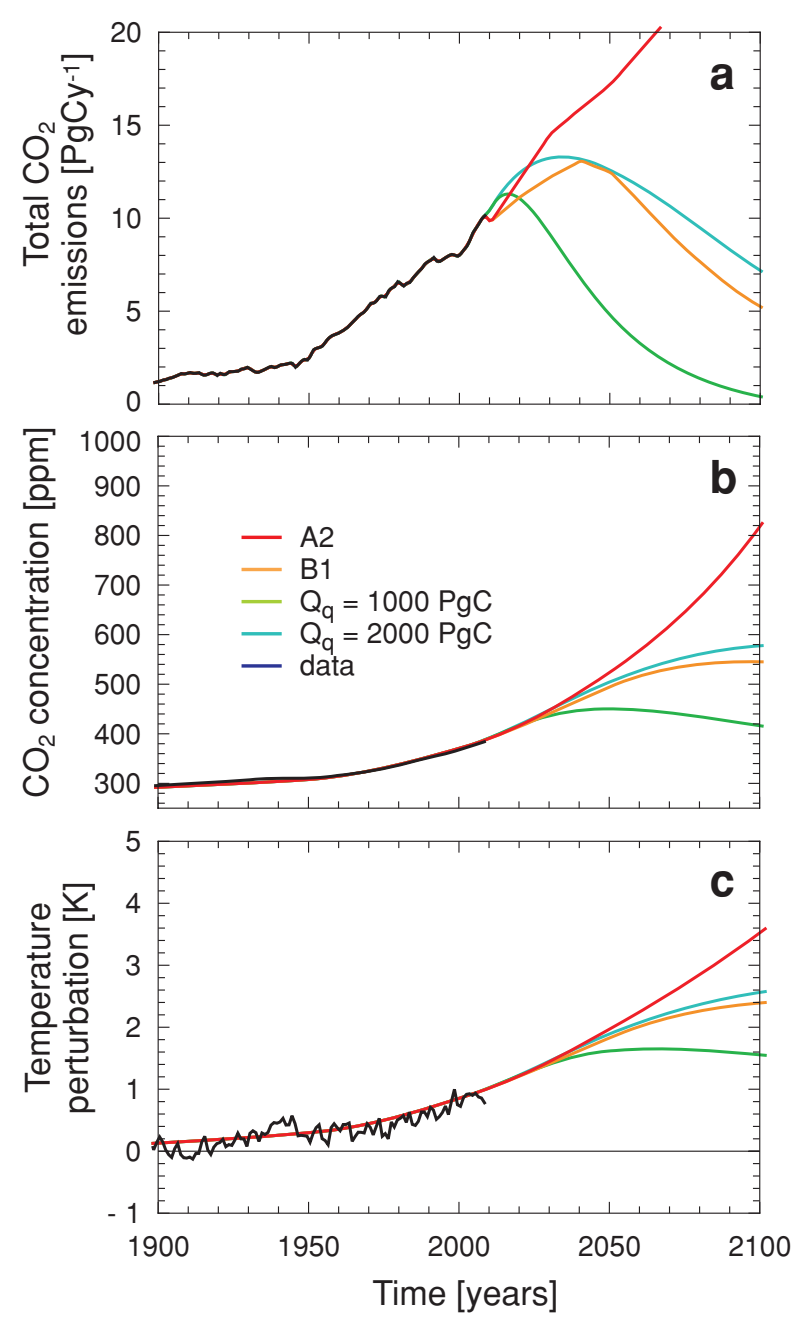

Fig. 3. Trajectories of $\mathrm{CO}_{2}$ emissions, $\mathrm{CO}_{2}$ concentrations and temperature from non-linear box model, with four emissions trajectories for $F_{\text {Foss }}$ : IPCC SRES marker scenarios A2 and B1 (Nakicenovic et al., 2000), and smooth capped trajectories (eq. 9 and Fig. 1) with all-time cumulative emissions $Q_{\mathrm{q}}=1000$ and $2000 \mathrm{PgC}$ and mitigation start time $t_{\mathrm{m}}=2011$. See Appendix C for data sources. Radiative forcing is from $\mathrm{CO}_{2}$ only.

2031. (Emissions up to $t_{\mathrm{m}}$ are assumed to continue growing exponentially; see eq. 9). As $Q_{\mathrm{q}}$ decreases, the required mitigation rate $m$ increases sharply, and higher rates $m$ are needed as $t_{\mathrm{m}}$ becomes later. This figure quantifies the increase in the mitigation challenge (specified by $m$ ) with delay (specified by $t_{\mathrm{m}}$ ).

Figure 1c shows an alternative 'discontinuous-slope' model for capped future emissions,

$$
F_{\mathrm{Foss}}(t)= \begin{cases}\text { observations } & \left(t \leq t_{1}\right), \\ F_{\mathrm{m}} \exp \left(r\left(t-t_{\mathrm{m}}\right)\right) & \left(t_{1}<t \leq t_{\mathrm{m}}\right), \\ F_{\mathrm{m}} \exp \left(-m\left(t-t_{\mathrm{m}}\right)\right) & \left(t>t_{\mathrm{m}}\right)\end{cases}
$$
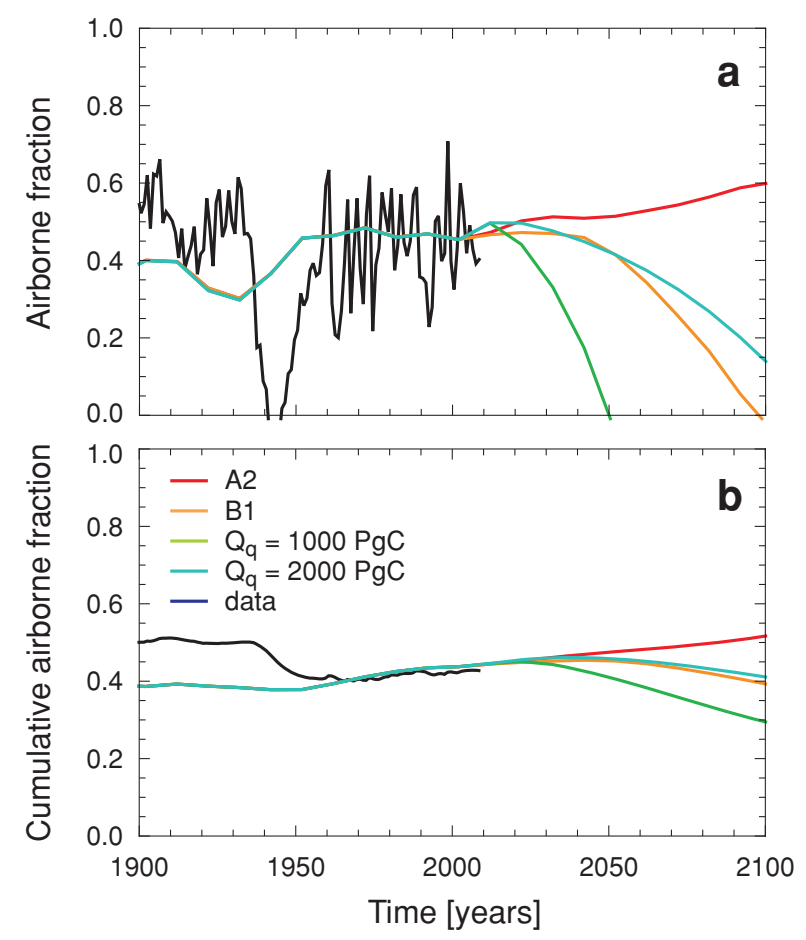

Fig. 4. Trajectories of airborne fraction and cumulative airborne fraction from non-linear box model, for the same conditions as in Fig. 3. See Appendix C for data sources.

These trajectories have a slope discontinuity at the mitigation start time $t_{\mathrm{m}}$, and are therefore ignore the effects of technological inertia in propagating patterns of $\mathrm{CO}_{2}$ emissions and carbon intensities over decades (Raupach et al., 2007). They provide an extreme test of the path dependence of parameters in eq. (8).

\section{Results}

\subsection{Non-linear box model with radiative forcing from $\mathrm{CO}_{2}$ only}

Figure 3 shows trajectories of total $\mathrm{CO}_{2}$ emissions $\left(F_{\text {Foss }}+\right.$ $\left.F_{\text {LUC }}\right), \mathrm{CO}_{2}$ concentrations and temperature from the nonlinear box model, with forcing from $\mathrm{CO}_{2}$ only, under four $\mathrm{CO}_{2}$ emissions scenarios: IPCC SRES A2 and B1 marker scenarios (Nakicenovic et al., 2000), and smooth capped trajectories (eq. 9, Fig. 1a) with $Q_{\mathrm{q}}=1000$ and $2000 \mathrm{PgC}$. Observed data (shown as black lines) are from sources specified in Appendix C.

With forcing from the IPCC SRES A2 and B1 marker scenarios, the temperature trajectories are well within the range from full climate models in the IPCC Fourth Assessment (IPCC, 2007b), although slightly lower than best-estimate IPCC projections (consistent with the omission of non- $\mathrm{CO}_{2}$ forcings in Fig. 3). Temperature trajectories with capped emissions decline after a peak temperature is reached, but only slowly (Lowe et al., 2009; Solomon et al., 2009) (also see Figs 5-8). 

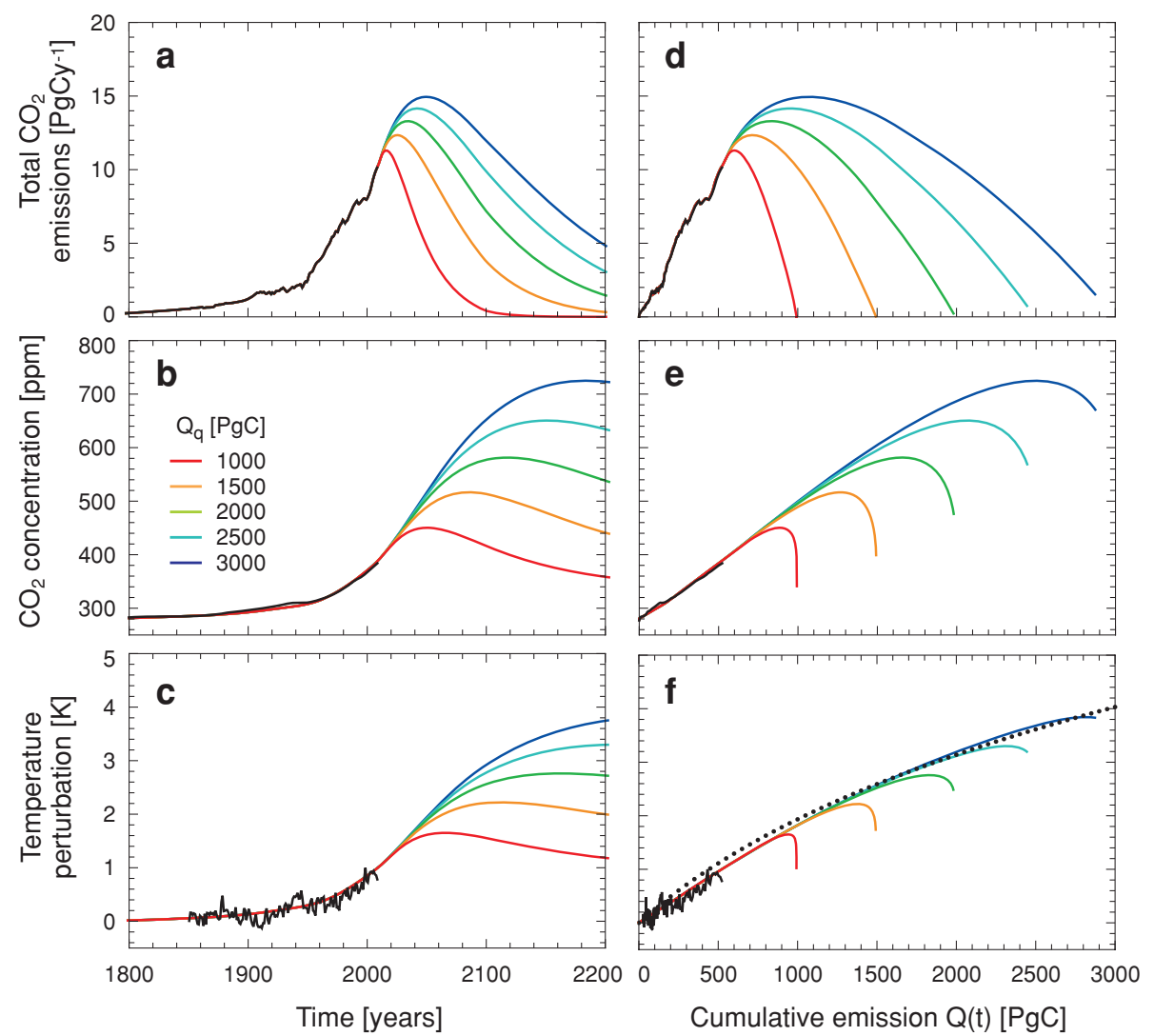

Fig. 5. Total $\mathrm{CO}_{2}$ emissions ( $F_{\text {Foss }}+F_{\mathrm{LUC}}$ ), $\mathrm{CO}_{2}$ concentrations and temperatures from the nonlinear box model (coloured curves), for smooth capped $\mathrm{CO}_{2}$ emissions trajectories (eq. (9)) with all-time cumulative emission $Q_{\mathrm{q}}$ from 1000 to $3000 \mathrm{PgC}$ and mitigation start time fixed at $t_{\mathrm{m}}=$ 2011, as in Fig. 1a. Black curves are observations (see Appendix $\mathrm{C}$ for data sources). Radiative forcing is from $\mathrm{CO}_{2}$ only. Quantities are plotted against time in left panels $(\mathrm{a}, \mathrm{b}, \mathrm{c})$ and cumulative $\mathrm{CO}_{2}$ emissions $Q(t)$ in right panels (d, e, f). Dotted curve in Fig. $5 \mathrm{f}$ is from the algebraic expression for $T_{\mathrm{p}}\left(Q_{\mathrm{p}}\right)$, eq. 8, with reference parameters.

Figure 4 shows the modelled $\mathrm{CO}_{2}$ airborne fraction (AF, over annual increments) and cumulative airborne fraction (CAF, defined above), for the same scenarios and conditions as Fig. 3. Agreement with past data (derived from sources in Appendix C) is broadly good, although with departures before 1950 when anthropogenic forcing of the carbon cycle was relatively much weaker than in recent decades. The cumulatively smoothed character of the CAF means that there is much less interannual variability in observations of the CAF than the AF, and also that there is less variation future projections of the CAF than the AF. By 2100, the CAF is projected to be about 0.5 (A2 emissions scenario) and 0.4 (B1), respectively, whereas the AF projections are $0.6(\mathrm{~A} 2)$ and $0(\mathrm{~B} 1)$.

Figure 5 shows total $\mathrm{CO}_{2}$ emissions $\left(F_{\text {Foss }}+F_{\text {LUC }}\right), \mathrm{CO}_{2}$ concentration and temperature from the non-linear box model, for smooth capped $\mathrm{CO}_{2}$ emissions trajectories (eq. 9) with alltime quotas $Q_{\mathrm{q}}$ from 1000 to $3000 \mathrm{PgC}$, and radiative forcing from $\mathrm{CO}_{2}$ only. In the left panels (Figs $5 \mathrm{a}-\mathrm{c}$ ) the trajectories are plotted conventionally against time, while in the corresponding right panels (Figs $5 \mathrm{~d}-\mathrm{f}$ ) they are plotted against the cumulative emission to time $t, Q(t)$. Plots using this 'cumulative emission clock' take the form of curves such as $\left[\mathrm{CO}_{2}\right](Q)$ and $T(Q)$, in which time varies parametrically along each curve.

Three results are evident in Fig. 5. First, there are successive delays between the times of peak emissions, peak $\mathrm{CO}_{2}$ concentration and peak temperature, both in the plots against $t$ (Figs 5a-c) and against $Q(t)$ (Figs $5 \mathrm{~d}-\mathrm{f}$ ). The delays become greater at higher quotas $Q_{\mathrm{q}}$ and therefore higher peak warmings.

Secondly, the temperature trajectories $T(Q)$ in Fig. $5 f$ (using the cumulative emission clock) show an approximate collapse to a common curve up to near the point of maximum temperature, which occurs at time $t_{\mathrm{p}}$ or at cumulative emission $Q_{\mathrm{p}}=$ $Q\left(t_{\mathrm{p}}\right)$. Temperatures fall below this curve at later times. The common curve is approximately represented by the dotted line in Fig. 5f, which provides a point of reference (it represents the algebraic expression for peak warming, eq. 8, as described later).

Thirdly, by the time $t_{\mathrm{p}}$ of peak temperature, most of the total cumulative emission quota has already been released. The maximum temperature $\left[T_{\mathrm{p}}=T\left(t_{\mathrm{p}}\right)\right]$ occurs at a cumulative emission $Q_{\mathrm{p}}$ which is less than the all-time quota $Q_{\mathrm{q}}$ by only about $2 \%$ at $Q_{\mathrm{q}}=1000 \mathrm{PgC}$ and $10 \%$ at $Q_{\mathrm{q}}=3000 \mathrm{PgC}$. 

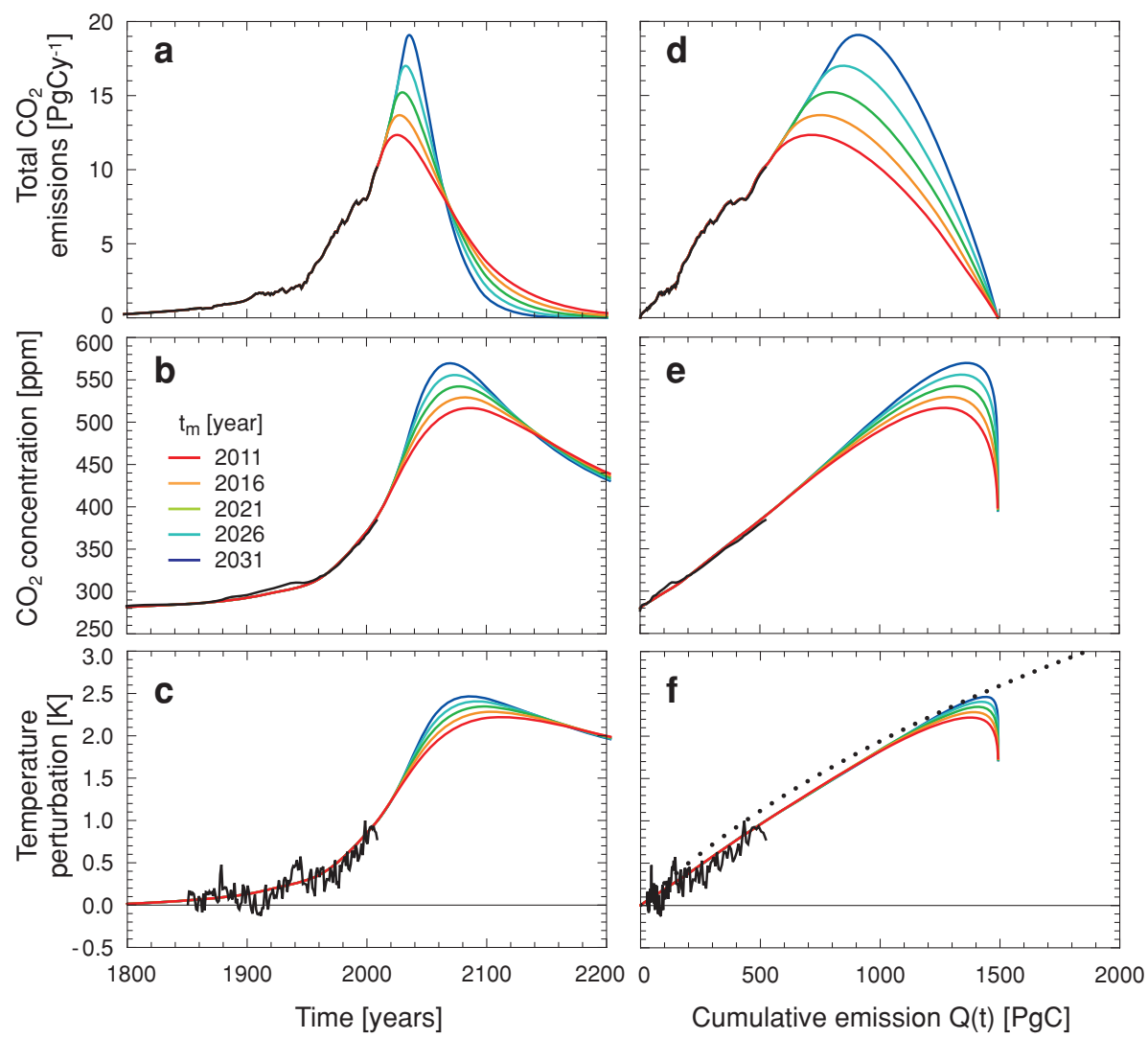

Fig. 6. Total $\mathrm{CO}_{2}$ emissions ( $F_{\mathrm{Foss}}+F_{\mathrm{LUC}}$ ), $\mathrm{CO}_{2}$ concentrations and temperatures from the nonlinear box model (coloured curves), for smooth capped $\mathrm{CO}_{2}$ emissions trajectories (eq. 9) with mitigation start time $t_{\mathrm{m}}$ varying from 2011 to 2031 and all-time cumulative emission fixed at $Q_{\mathrm{q}}=$ $1500 \mathrm{PgC}$, as in Fig. 1b. Other details are as for Fig. 5.

It is important to test the extent to which the results in Fig. 5 (and others discussed later) depend upon properties of the assumed family of $\mathrm{CO}_{2}$ emissions trajectories (eq. 9). One such property is that the time of the peak in emissions occurs progressively later with larger all-time cumulative emissions $Q_{\mathrm{q}}$. Although this behaviour is likely for emissions scenarios which peak and decline to yield finite all-time integrals, it is not inevitable. Therefore, the analysis of Fig. 5 is repeated in Figs 6 and 7 with two alternative families of emissions trajectories which decouple the relationship between $Q_{\mathrm{q}}$ and the time of peak emissions. Figure 6 uses a set of emissions trajectories with the same $Q_{\mathrm{q}}$ but different times for peak emissions, whereas Fig. 7 uses emissions trajectories with the same time of peak emissions but varying $Q_{\mathrm{q}}$.

The emissions trajectories in Fig. 6 are obtained from the smooth capped trajectory family, eq. (9), by varying the mitigation start time $t_{\mathrm{m}}$ from 2011 to 2031 with fixed $Q_{\mathrm{q}}(1500 \mathrm{PgC})$ as in Fig. 1b. Peak emissions occur within a few years of $t_{\mathrm{m}}$ for all these trajectories, but the rate at which emissions fall after the peak increases rapidly with delay in starting mitigation. This occurs because increased delay (later $t_{\mathrm{m}}$ ) increases the cumulative emissions expended before $t_{\mathrm{m}}$, so a faster decline after the peak in emissions is necessary to meet the constraint of a fixed $Q_{\mathrm{q}}$. For this family of emissions trajectories, the times of peak $\mathrm{CO}_{2}$ concentration and peak temperature occur progressively earlier for progressively later times of peak emissions (Figs 6a-c). This initially counterintuitive behaviour, which contrasts with Figs 5a-c, occurs because of the progressively sharper fall in emissions with delay in $t_{\mathrm{m}}$. However, when trajectories are plotted against the cumulative emission clock (Figs $5 \mathrm{~d}-\mathrm{f}$ ), the expected order of peak occurrences is recovered: delay in $t_{\mathrm{m}}$ moves the peaks in emissions, $\mathrm{CO}_{2}$ concentration and temperature to larger $Q(t)$.

The other two main results from Fig. 5 [the collapse of $T(Q)$ to a common curve up to near $Q_{\mathrm{p}}=Q\left(t_{\mathrm{p}}\right)$, and the fact that $Q_{\mathrm{p}}$ is nearly all of the all-time quota $Q_{\mathrm{q}}$ ] are also evident in Fig. 6.

In Fig. 7, emissions trajectories with the same time of peak emissions but varying $Q_{\mathrm{q}}$ are obtained from the discontinuousslope emissions trajectory (eq. 12) with mitigation start time $t_{\mathrm{m}}=2011$ as in Fig. 1c, thus forcing the peak emission to occur at this time for all $Q_{\mathrm{q}}$. In this case, all three main results from Fig. 5 are also observed, but the common curve to which $T(Q)$ collapses (for $Q$ nearly up to $Q_{\mathrm{p}}$ ) is slightly lower than the 

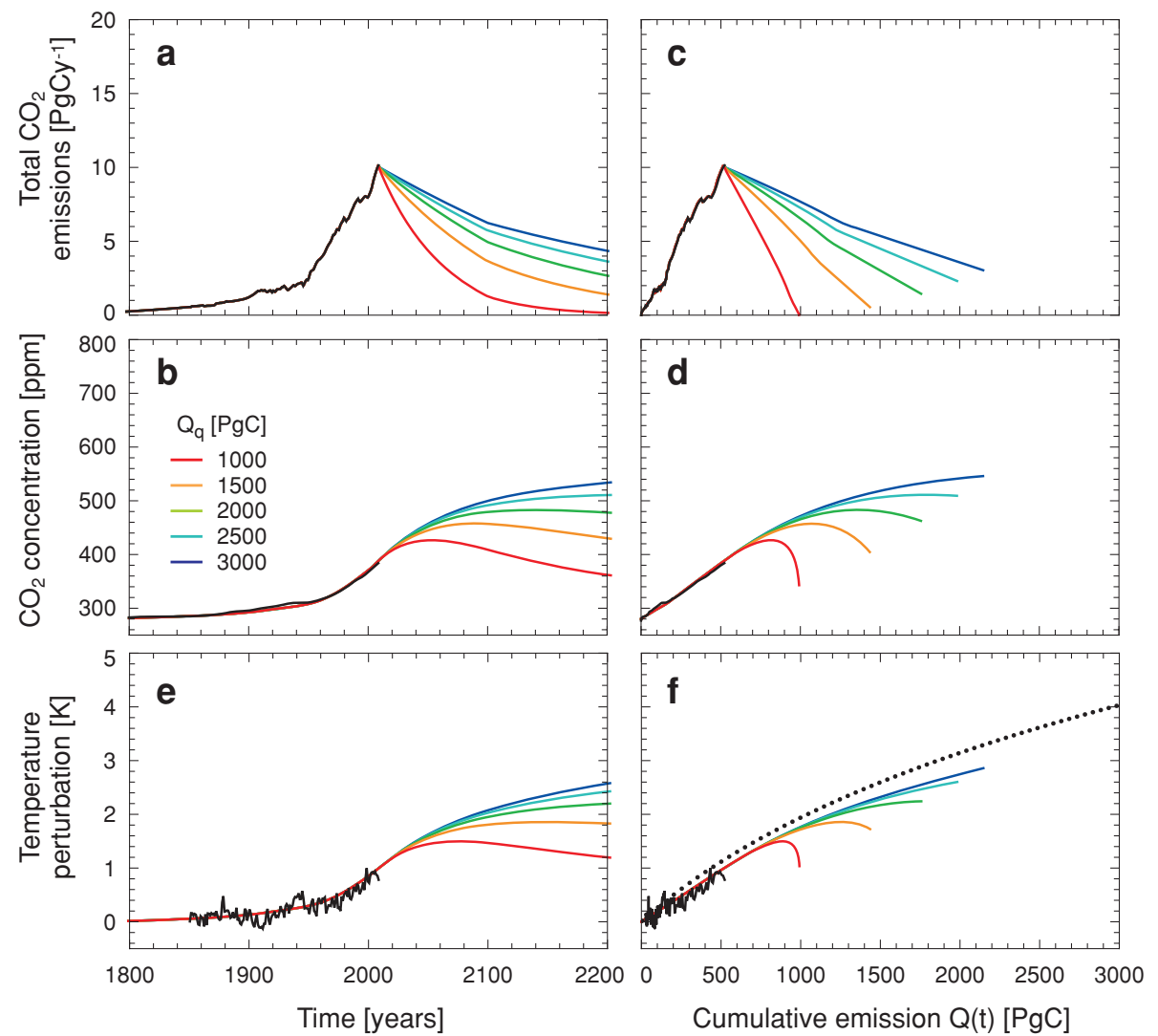

Fig. 7. Total $\mathrm{CO}_{2}$ emissions ( $F_{\text {Foss }}+F_{\mathrm{LUC}}$ ), $\mathrm{CO}_{2}$ concentrations and temperatures from the nonlinear box model, for discontinuous-slope capped $\mathrm{CO}_{2}$ emissions trajectories (eq. (12)) with all-time cumulative emission $Q_{\mathrm{q}}$ from 1000 to $3000 \mathrm{PgC}$ and mitigation start time fixed at $t_{\mathrm{m}}=2011$, as in Fig. 1c. Other details are as for Fig. 5.

curve in Figs 5 and 6. Therefore, this common curve is weakly dependent on the family of emissions trajectories.

\subsection{Non-linear box model with multigas radiative forcing}

Here we examine the response of temperature trajectories to radiative forcing from multiple agents, to assess the effect of non- $\mathrm{CO}_{2}$ radiative forcing on the collapse of $T(Q)$ to a common curve. For these calculations, future anthropogenic emissions of the non- $\mathrm{CO}_{2}$ greenhouse gases considered here $\left(\mathrm{CH}_{4}, \mathrm{~N}_{2} \mathrm{O}\right.$ and halocarbons, represented only by CFCs) were prescribed using a simple illustrative scenario given in Appendix A. The (negative) radiative forcing from aerosols was assumed to be proportional to total $\mathrm{CO}_{2}$ emissions (Section 2 and Appendix A).

The multigas radiative forcings following from these assumptions are shown in Fig. 8a. The total radiative forcing (blue curve) is approximately equal to the $\mathrm{CO}_{2}$-only forcing (red curve) in 2000 , consistent with the approximate cancellation in the recent past of radiative forcing from non- $\mathrm{CO}_{2}$ gases and non-gaseous agents. The estimated total radiative forcing in 2005 was +1.6
(0.6-2.4) $\mathrm{W} \mathrm{m}^{-2}$ (IPCC, 2007b), including contributions of $+1.6 \mathrm{~W} \mathrm{~m}^{-2}$ from $\mathrm{CO}_{2},+1.4 \mathrm{~W} \mathrm{~m}^{-2}$ from non- $\mathrm{CO}_{2}$ gases $\left(\mathrm{CH}_{4}, \mathrm{~N}_{2} \mathrm{O}\right.$ and others), and $-1.5 \mathrm{~W} \mathrm{~m}^{-2}$ from non-gaseous agents, mainly direct and indirect aerosol forcing of $-1.2(-2.7$ to $-0.4) \mathrm{W} \mathrm{m}^{-2}$, which contributed the largest uncertainty. In future, however, the positive forcing from non- $\mathrm{CO}_{2}$ gases is likely to increase and negative forcing from aerosols is likely to decrease, as suggested by detailed models of non- $\mathrm{CO}_{2}$ radiative forcings (Strassmann et al., 2009). This means that total radiative forcing in the long-term (century scale) future is likely to significantly exceed the $\mathrm{CO}_{2}$-only forcing. Figure $8 \mathrm{a}$ reflects this expectation, and also suggests that there will be a short-term (decadal-scale) increase in negative radiative forcing from aerosols as $\mathrm{CO}_{2}$ emissions increase, causing total radiative forcing to fall below the $\mathrm{CO}_{2}$-only forcing for a few decades.

The temperature trajectories resulting from these radiative forcings are shown in Figs $8 \mathrm{~b}$ and c, plotted respectively against $t$ and the cumulative emission clock $Q(t)$. In the immediate future, temperatures fall below the common curve for $\mathrm{CO}_{2}$-only forcing, but temperatures subsequently rise to peaks above this 

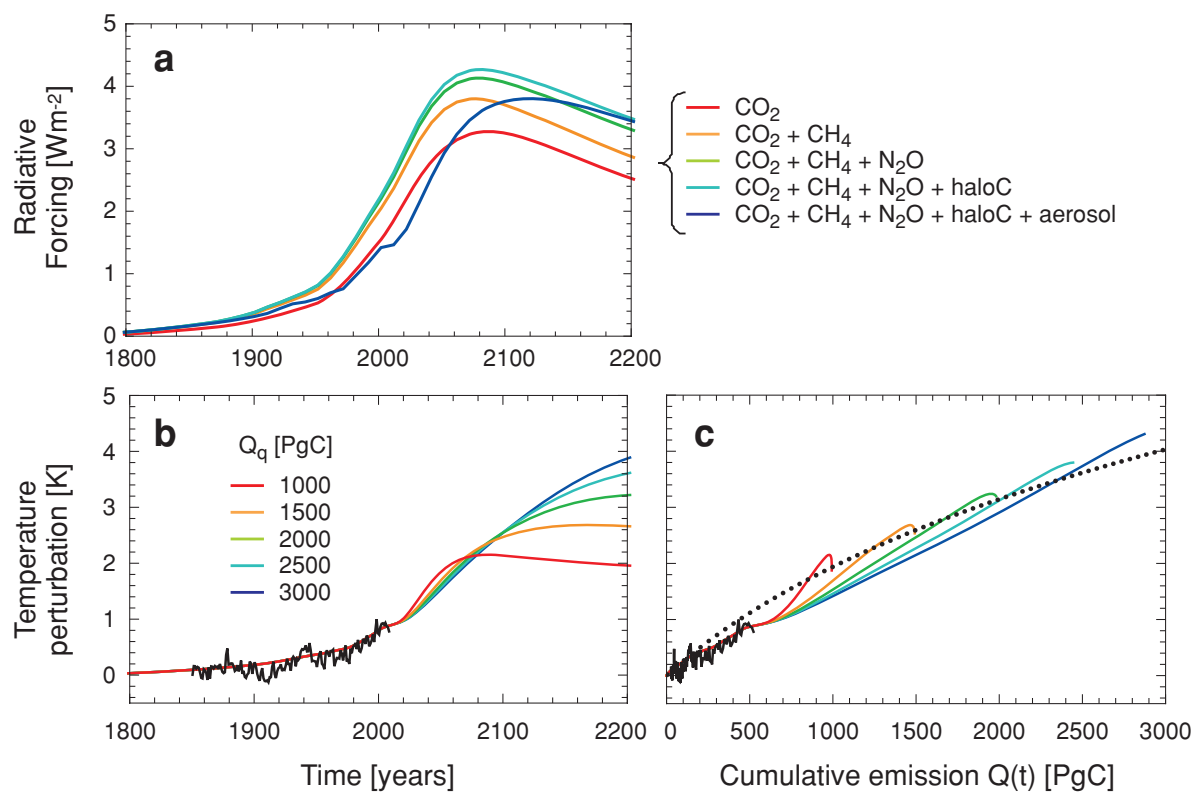

Fig. 8. (a) Cumulative contributions to multi-gas radiative forcing from $\mathrm{CO}_{2}, \mathrm{CH}_{4}, \mathrm{~N}_{2} \mathrm{O}$, halocarbons and aerosols. Radiative forcing for $\mathrm{CO}_{2}$ assumes smooth capped $\mathrm{CO}_{2}$ emissions trajectory (eq. 9) with $Q_{\mathrm{q}}=1500 \mathrm{PgC}$ and $t_{\mathrm{m}}=2011$. Radiative forcing for $\mathrm{CH}_{4}, \mathrm{~N}_{2} \mathrm{O}$ and halocarbons (represented by CFC-11 and CFC-12) uses a simple illustrative emissions scenario (Appendix A). Radiative forcing for aerosols is assumed proportional to $\mathrm{CO}_{2}$ emissions (Appendix A). (b) Temperature trajectories from nonlinear box model plotted against time $t$, with multigas radiative forcing assuming smooth capped $\mathrm{CO}_{2}$ emissions trajectories (eq. (9)) with $Q_{\mathrm{q}}$ from 1000 to $3000 \mathrm{PgC}$ and $t_{\mathrm{m}}=2011$, and multigas forcing as in (a). (c) Temperature trajectories as in (b) but plotted against cumulative $\mathrm{CO}_{2}$ emissions clock $Q(t)$. Other details are as for Fig. 5.

curve because of the extra radiative forcing from non- $\mathrm{CO}_{2}$ gases and the progressive decrease in negative forcing from aerosols.

\subsection{Path dependence}

We now assess the path dependence of the parameters $\lambda_{\mathrm{p}}$ and $A_{\mathrm{p}}$ in eq. (8). It is shown in Appendix B that the peak climate sensitivity $\lambda_{\mathrm{p}}$ depends on the trajectory of radiative forcing, unlike the equilibrium climate sensitivity $\lambda_{\mathrm{q}}$ which (under a linear climate model) is independent of the path to equilibrium. System inertia suggests that $\lambda_{\mathrm{p}}$ is less than $\lambda_{\mathrm{q}}$, because the system at time $t_{\mathrm{p}}$ has realised only a fraction of its ultimate equilibrium response. Therefore, it is appropriate to investigate the ratio $\lambda_{\mathrm{p}} / \lambda_{\mathrm{q}}$ as a measure of the path dependence of $\lambda_{\mathrm{p}}$.

By contrast, the CAF $A(t)$ is approximately steady in conditions where emissions are increasing approximately exponentially, as has occurred over the past century or more. As the system approaches a long-term equilibrium in which emissions are zero, $A(t)$ is expected to decline (Fig. 4). Therefore, a suitable measure of path dependence in $A_{\mathrm{p}}$ is the ratio $A_{\mathrm{p}} / A_{\mathrm{m}}$, where $A_{\mathrm{m}}$ is the CAF at the time $t_{\mathrm{m}}$ when mitigation begins.

Figure 9 shows the calculated dependence (from the nonlinear box model) of the ratios $\lambda_{\mathrm{p}} / \lambda_{\mathrm{q}}$ and $A_{\mathrm{p}} / A_{\mathrm{m}}$ on the all-time cumulative emission $Q_{\mathrm{q}}$, for three emissions scenarios: first (coloured lines) for $\mathrm{CO}_{2}$ forcing with smooth capped $\mathrm{CO}_{2}$ emissions trajectories (eq. 9 and Fig. 5) in which the mitigation start time $t_{\mathrm{m}}$ varies from 2011 to 2031 as in Fig. 6; second (solid black curve) for $\mathrm{CO}_{2}$ forcing with discontinuous-slope capped $\mathrm{CO}_{2}$ emissions trajectories, taking $t_{\mathrm{m}}=2011$ as in Fig. 7; and third (grey curve) for multigas radiative forcing as in Fig. 8. These three sets of scenarios test the response of $\lambda_{\mathrm{p}} / \lambda_{\mathrm{q}}$ and $A_{\mathrm{p}} / A_{\mathrm{m}}$ to variations of future $\mathrm{CO}_{2}$ emissions trajectories with several alternative relationships between the all-time cumulative quota $Q_{\mathrm{q}}$ and the time of peak emissions (as in Figs 5-7), and also to the inclusion of non- $\mathrm{CO}_{2}$ forcings (as in Fig. 8).

Figure $9 \mathrm{a}$ shows that $\lambda_{\mathrm{p}} / \lambda_{\mathrm{q}}$ increases with $Q_{\mathrm{q}}$, consistent with the above expectation. There is very little dependence on the time of peak emissions when this is varied independently of $Q_{\mathrm{q}}$ (comparing the coloured lines in Fig. 9a), and a response of only a few percent to the inclusion of non- $\mathrm{CO}_{2}$ forcings as in Fig. 8 (comparing the red and grey lines). There is a slightly larger difference between the smooth capped and discontinuousslope emissions trajectories (comparing the red and solid black lines).

In summary, the path dependence in $\lambda_{\mathrm{p}} / \lambda_{\mathrm{q}}$ is not large, and $\lambda_{\mathrm{p}} / \lambda_{\mathrm{q}} \approx 0.6$ to within $10 \%$ for the scenarios investigated. Combining this value with $\lambda_{\mathrm{q}}=1.235 \mathrm{~K} \mathrm{~W}^{-1} \mathrm{~m}^{2}$ for the three-term HadCM3 climate response function ( $\mathrm{Li}$ and Jarvis, 2009), we a find reference value for $\lambda_{\mathrm{p}}$ of $0.74 \mathrm{~K} \mathrm{~W}^{-1} \mathrm{~m}^{2}$. We have also confirmed that similar values of $\lambda_{\mathrm{p}}$ are obtained with other climate response functions (Den Elzen et al., 1999; Trudinger and Enting, 2005) with shorter climate response times, arising for 

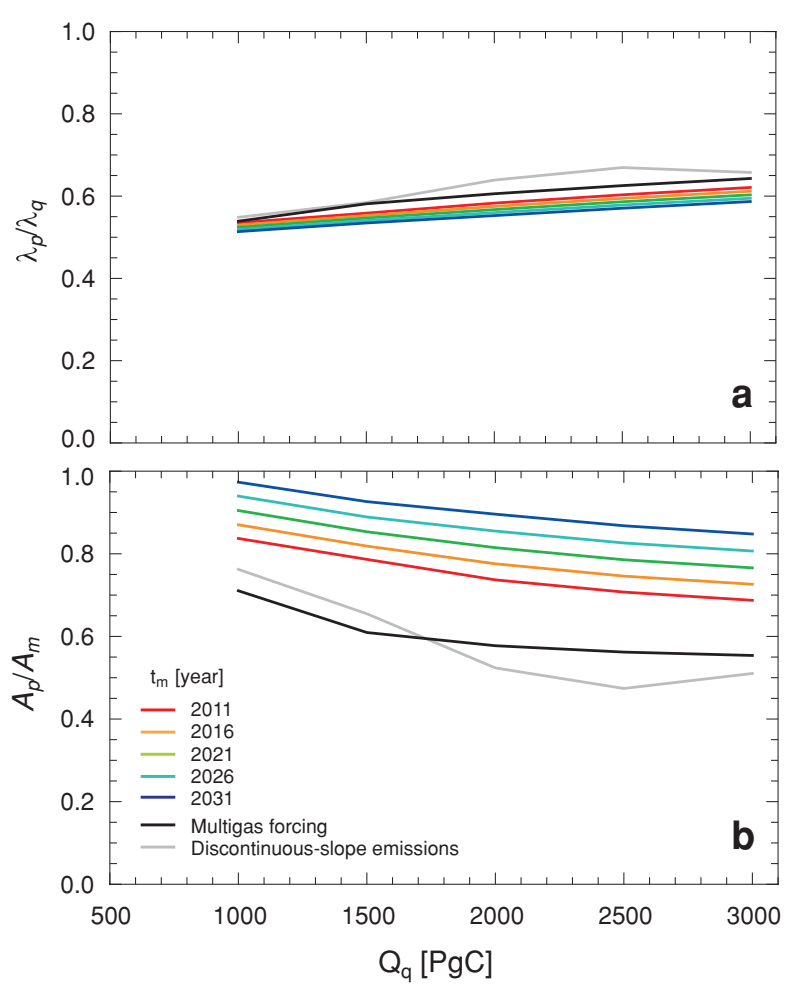

Fig. 9. (a) Ratio $\lambda_{\mathrm{p}} / \lambda_{\mathrm{q}}$ and (b) ratio $A_{\mathrm{p}} / A_{\mathrm{m}}$, plotted against all-time cumulative $\mathrm{CO}_{2}$ emissions $Q_{\mathrm{q}}$. Coloured lines are for $\mathrm{CO}_{2}$ forcing only as in Figs 5 and 6, using smooth capped $\mathrm{CO}_{2}$ emissions trajectories (eq. 9) and mitigation start time $t_{\mathrm{m}}$ varying from 2011 to 2031. Solid black curve is for $\mathrm{CO}_{2}$ forcing only as in Fig. 7, using discontinuous-slope capped $\mathrm{CO}_{2}$ emissions trajectories with $t_{\mathrm{m}}=$ 2011. Grey curve is for multigas radiative forcing as in Fig. 8.

example from lower ocean mixing. These climate response functions have lower equilibrium sensitivities $\lambda_{\mathrm{q}}$. However, they also yield larger $\lambda_{\mathrm{p}} / \lambda_{\mathrm{q}}$ values than those in Fig. 9a (results not shown), leading to similar values for $\lambda_{\mathrm{p}}$. The peak sensitivity $\lambda_{p}$ is a measure of transient rather than equilibrium climate response, and is therefore relatively consistent across climate models with similar transient responses even if their long-term equilibrium responses are different. Climate models tend to have similar transient responses because they are constrained by observed twentieth century warming (Frame et al., 2006).

Figure $9 \mathrm{~b}$ shows that $A_{\mathrm{p}} / A_{\mathrm{m}}$ decreases with increasing $Q_{\mathrm{q}}$ in most cases. There is a wider variation in $A_{\mathrm{p}} / A_{\mathrm{m}}$ than in $\lambda_{\mathrm{p}} / \lambda_{\mathrm{q}}$, particularly as the time of peak emissions is delayed by delaying the mitigation start time $t_{\mathrm{m}}$ (comparing the coloured curves in Fig. 9b). This occurs because $A(t)$ increases with time for strongly increasing emissions, and decreases with time when emissions decrease significantly (Fig. 4b).

For cumulatively capped $\mathrm{CO}_{2}$ emissions scenarios with an immediate start to mitigation $\left(t_{\mathrm{m}}=2011\right)$, Fig. $9 \mathrm{~b}$ shows that $A_{\mathrm{p}} / A_{\mathrm{m}}$ is within $15 \%$ of 0.7 . Taking the present (2005-2009)

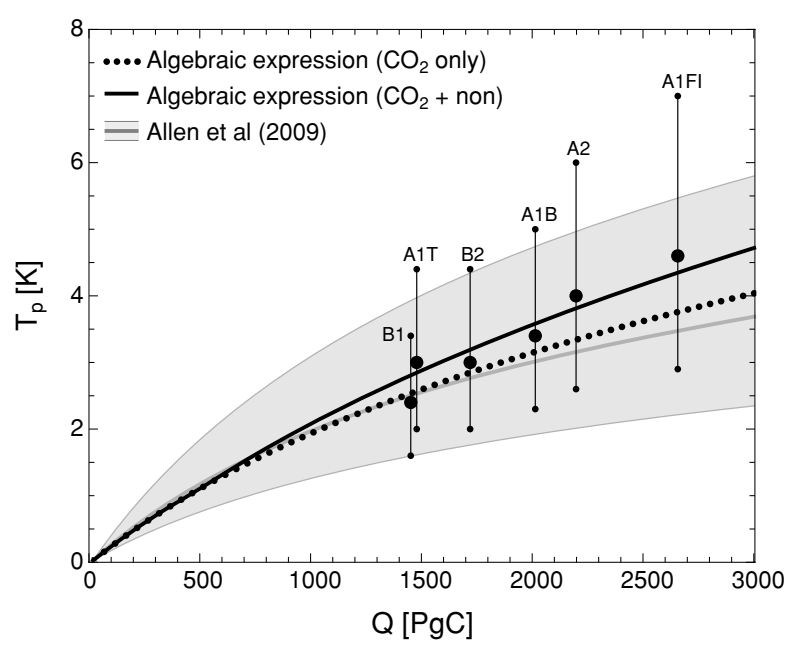

Fig. 10. Peak temperature relative to pre-industrial times, $T_{\mathrm{p}}$, as a function of all-time cumulative emission $Q_{\mathrm{q}}$. Dotted line: algebraic expression, eq. (8), with reference parameters, including no non- $\mathrm{CO}_{2}$ radiative forcing. Solid black line: Eq. (8) with non- $\mathrm{CO}_{2}$ forcing from eq. (13), taking $s_{\mathrm{N}}=0.00033 \mathrm{~W} \mathrm{~m}^{-2} \mathrm{PgC}^{-1}$. Grey lines:

approximations to results of Allen et al. (2009), representing median and $5 \%$ and $95 \%$ confidence intervals in the distribution of $T_{\mathrm{p}}$ with given $Q_{\mathrm{p}}$. The median curve is $T_{\mathrm{p}}\left(Q_{\mathrm{p}}\right)=2.076 \ln \left(1+Q_{\mathrm{p}} / 621.9\right)$, a fit to the white crosses in Fig. 2 of Allen et al. (2009), and the 5\% and 95\% curves are multiples of this curve from their Fig. 3. Black points: IPCC scenario results for $(Q(2100), T(2100))$.

CAF to be $A_{\mathrm{m}}=0.42$ (Canadell et al., 2007; Le Quere et al., 2009; Fig. 4b), we obtain $A_{\mathrm{p}}=0.29$ as a reference value.

The trends in $\lambda_{\mathrm{p}} / \lambda_{\mathrm{q}}$ and $A_{\mathrm{p}} / A_{\mathrm{m}}$ with $Q_{\mathrm{q}}$ in Figs $9 \mathrm{a}$ and $\mathrm{b}$ are not only opposite but are approximately complementary. This may be partly attributable to the fact that both curves are strongly dependent on the penetration rate for a tracer into the ocean. This nearly complementary behaviour means that compensating errors are introduced into the expression for $T_{\mathrm{p}}\left(Q_{\mathrm{p}}\right)$, eq. (8), by variation of $\lambda_{\mathrm{p}} / \lambda_{\mathrm{q}}$ and $A_{\mathrm{p}} / A_{\mathrm{m}}$ with cumulative emissions expressed as either $Q_{\mathrm{q}}$ or $Q_{\mathrm{p}}$ (recalling that $Q_{\mathrm{p}}$ is typically $90 \%$ or more of $Q_{\mathrm{q}}$ ). The effects of variation of $Q_{\mathrm{p}}$ on the parameters $\lambda_{\mathrm{p}}$ and $A_{\mathrm{p}}$ in eq. (8) are therefore relatively small.

\subsection{Algebraic expression for peak warming}

The expression for $T_{\mathrm{p}}\left(Q_{\mathrm{p}}\right)$ in eq. (8) depends on four parameters, of which three $\left(\lambda_{\mathrm{p}}, A_{\mathrm{p}}, \gamma\right)$ are properties of the carbon-climate system and one $\left(R_{\mathrm{Np}}\right)$ is an additional forcing variable together with $Q_{\mathrm{p}}$. Reference values for these parameters are assigned as follows.

For the peak climate sensitivity $\left(\lambda_{\mathrm{p}}\right)$ and cumulative AF at time of peak temperature $\left(A_{\mathrm{p}}\right)$, we use the reference values $\lambda_{\mathrm{p}}=$ $0.74 \mathrm{~K} \mathrm{~W}^{-1} \mathrm{~m}^{2}$ and $A_{\mathrm{p}}=0.29$ (see previous subsection). This is motivated by the nearly complementary behaviour of $\lambda_{\mathrm{p}} / \lambda_{\mathrm{q}}$ and $A_{\mathrm{p}} / A_{\mathrm{m}}$ with variation of $Q_{\mathrm{p}}$. 

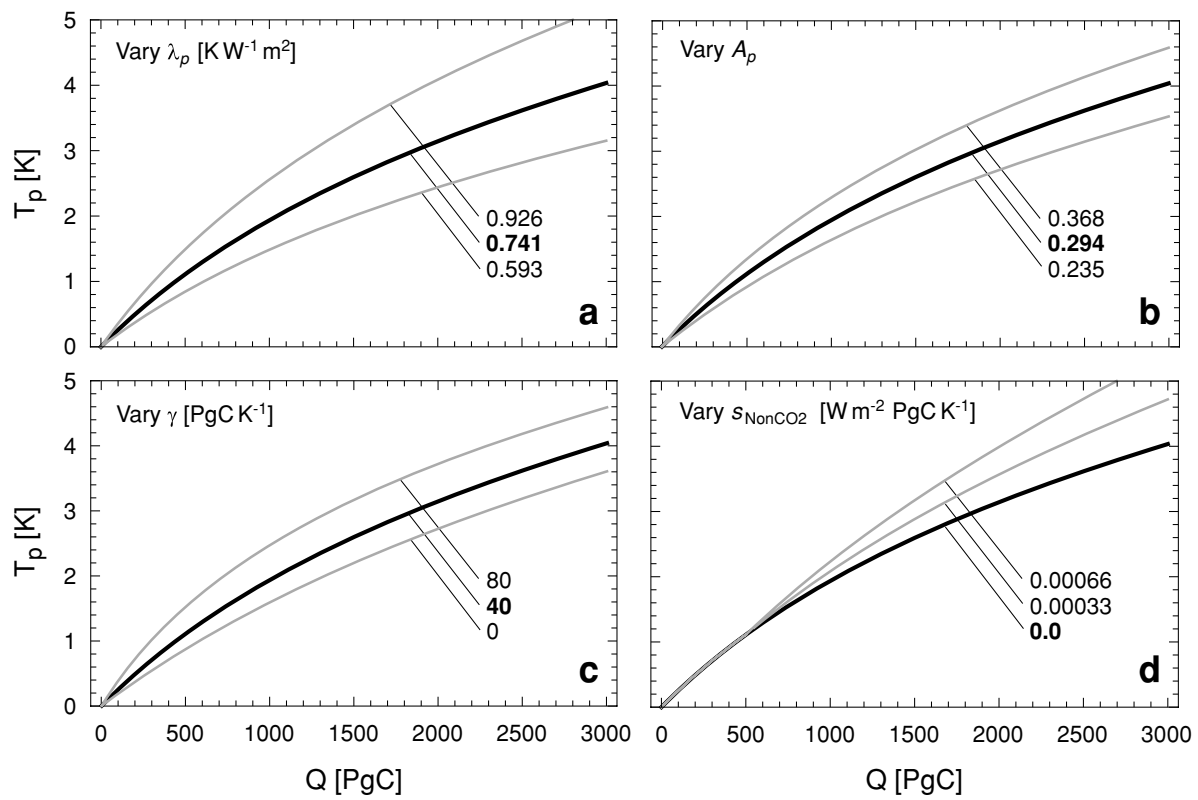

Fig. 11. $T_{\mathrm{p}}\left(Q_{\mathrm{p}}\right)$ from eq. (8), showing effects of variation of $\lambda_{\mathrm{p}}, A_{\mathrm{p}}, \gamma$ and $s_{\mathrm{N}}$ through specified ranges around reference values (black lines and bold values).

The sensitivity of carbon pools to climate change $(\gamma)$ is chosen so that $g$, the gain in eq. (8), is typical of the gain due to climate responses of both land and ocean carbon pools found from models. The C4MIP study (Friedlingstein et al., 2006) compared 11 models forced with an A2 emissions scenario, finding $g \approx 0.15$ (range 0.04-0.31). A later study (Sitch et al., 2008), with five models forced with several emissions scenarios, found similarly scattered but higher values of $g$ (range $0.14-0.43$ ). We choose $\gamma$ conservatively to give a gain $g=0.15$ when $Q_{\mathrm{p}}=1500 \mathrm{PgC}$ and with other parameters as above, implying a reference value $\gamma=40 \mathrm{PgC} \mathrm{K}^{-1}$.

We take a reference value of the non- $\mathrm{CO}_{2}$ radiative forcing at the time of peak temperature, $R_{\mathrm{Np}}$, to be zero. This is consistent with the approximate cancellation in the recent past of forcing from non- $\mathrm{CO}_{2}$ gases and non-gaseous agents. However, as noted in Section 3.2 and Fig. 8a, such cancellation is not likely to continue. Radiative forcing from aerosols is likely to become less negative (Ramanathan and Feng, 2008) and the positive forcing from non- $\mathrm{CO}_{2}$ gases is likely to increase (Strassmann et al., 2009), driven partly by increasing $\mathrm{CH}_{4}$ and $\mathrm{N}_{2} \mathrm{O}$ emissions as agricultural production expands with world population and affluence. Both effects will increase $R_{\mathrm{Np}}$, with consequences to be assessed later.

Figure 10 shows the relationship $T_{\mathrm{p}}\left(Q_{\mathrm{p}}\right)$ from eq. (8), with parameters set to the above reference values (dotted curve). This is compared with two other sources of information. First, Allen et al. (2009) and Meinshausen et al. (2009) presented results from multiple carbon-climate models on the peak warming $T_{\mathrm{p}}$ in response to given cumulative emissions. The grey curves in Fig. 10 show the median estimate of $T_{\mathrm{p}}$ and the values at $5 \%$ and $95 \%$ confidence intervals, from Allen et al. (2009). There is good agreement between the curve for $T_{\mathrm{p}}\left(Q_{\mathrm{p}}\right)$ from eq. (8) with reference parameters (including $R_{\mathrm{Np}}=0$ ), and the median curve from Allen et al. (2009). Both results consider radiative forcing from $\mathrm{CO}_{2}$ only.

The dotted curve in Fig. 10 is also plotted in each of Figs 5f, 6f, $7 \mathrm{f}$ and $8 \mathrm{f}$, for comparison with the nonlinear box model.

The second comparison in Fig. 10 is with IPCC scenario families. Because IPCC climate projections extend only to 2100 , which is earlier than their time of peak temperature, we plot points ( $Q(2100), T(2100))$ using temperatures and their uncertainty ranges in 2100 (IPCC, 2007b) and cumulative emissions to 2100 from marker scenarios (Nakicenovic et al., 2000). For $Q$ values less than about $2000 \mathrm{PgC}$ (encompassing the B1, A1T, B2 and $\mathrm{A} 1 \mathrm{~B}$ scenarios in order of increasing $Q$ ), there is agreement to within $10 \%$ between IPCC points, the curves from eq. (8) with $R_{\mathrm{Np}}=0$ (dotted curve) and the median curve from Allen et al. (2009). At $Q$ values above $2000 \mathrm{PgC}$ (encompassing the A2 and A1FI scenarios), the IPCC points fall above these curves. One possible reason is that both curves describe responses to $\mathrm{CO}_{2}$ forcing only, whereas the IPCC results include non- $\mathrm{CO}_{2}$ forcing.

To illustrate the possible role of non- $\mathrm{CO}_{2}$ forcing we assume that $R_{\mathrm{Np}}$ can be related to the $\mathrm{CO}_{2}$ forcing quantified by $Q_{\mathrm{p}}$. Such a relationship would be approximated if mitigation efforts were to be spread across anthropogenic greenhouse gases, so that scenarios with high cumulative future $\mathrm{CO}_{2}$ emissions would also have high ongoing radiative forcing from non$\mathrm{CO}_{2}$ agents, and conversely. Because $\mathrm{CO}_{2}$ and non- $\mathrm{CO}_{2}$ forcings are biophysically independent, this is clearly not a general 
proposition, although it is broadly consistent with detailed studies of non- $\mathrm{CO}_{2}$ forcing (Strassmann et al., 2009, their fig. 4). A possible simple relationship between $R_{\mathrm{Np}}$ and $Q_{\mathrm{p}}$, of linear form with a threshold, is

$R_{\mathrm{Np}}=s_{\mathrm{N}} \max \left(0, Q_{\mathrm{p}}-500 \mathrm{PgC}\right)$

where $s_{\mathrm{N}}\left[\mathrm{W} \mathrm{m}^{-2} \mathrm{PgC}^{-1}\right]$ is the incremental non- $\mathrm{CO}_{2}$ forcing per $\mathrm{PgC}$ of cumulative $\mathrm{CO}_{2}$ emissions above $500 \mathrm{PgC}$. The threshold is consistent with the approximate present cancellation of non$\mathrm{CO}_{2}$ radiative forcing from gaseous and non-gaseous agents. The reference case $\left(R_{\mathrm{Np}}=0\right)$ corresponds to $s_{\mathrm{N}}=0$.

The solid black curve in Fig. 10 shows $T_{\mathrm{p}}\left(Q_{\mathrm{p}}\right)$ from eq. (8), with $R_{\mathrm{Np}}$ described by eq. (13) with $s_{\mathrm{N}}=0.00033 \mathrm{~W} \mathrm{~m}^{-2} \mathrm{PgC}^{-1}$. This curve approximately matches the IPCC points, and can be regarded as the result for $T_{\mathrm{p}}$ from eq. (8) with explicit forcing from both $\mathrm{CO}_{2}$ and non- $\mathrm{CO}_{2}$ agents, along one line in the plane $\left(Q_{\mathrm{p}}, R_{\mathrm{Np}}\right)$ which describes a possible association between $Q_{\mathrm{p}}$ and $R_{\mathrm{Np}}$ from eq. (13).

\subsection{Sensitivities and uncertainties}

In Fig. 11, we assess the sensitivity of $T_{\mathrm{p}}\left(Q_{\mathrm{p}}\right)$ (from eqs. 8 and 13) to variations in the four parameters $\lambda_{\mathrm{p}}, A_{\mathrm{p}}, \gamma$ and $R_{\mathrm{Np}}$ (as set by $\left.s_{\mathrm{N}}\right)$. Variations of $\lambda_{\mathrm{p}}$ and $A_{\mathrm{p}}$ are by factors $(5 / 4,4 / 5)$ or increments of $(+25 \%,-20 \%)$ in each case, and variations of $\gamma$ and $s_{\mathrm{N}}$ are in additive increments from zero.

First we assess the peak climate sensitivity $\left(\lambda_{\mathrm{p}}\right)$. The largest uncertainty in $T_{\mathrm{p}}\left(Q_{\mathrm{p}}\right)$ stems from uncertainty in $\lambda_{\mathrm{p}}$, inherited mainly from uncertainty in the equilibrium climate sensitivity $\lambda_{\mathrm{q}}$, with an additional smaller contribution from the path dependence of $\lambda_{\mathrm{p}}$. Variation of $\lambda_{\mathrm{p}}$ in Fig. 11a by $(+25 \%,-20 \%)$ leads to a variation in $T_{\mathrm{p}}$ of about $(+1.2,-1) \mathrm{K}$ at $Q_{\mathrm{p}}=2000 \mathrm{PgC}$, where the reference $T_{\mathrm{p}}$ is $3.1 \mathrm{~K}$. The range used for $\lambda_{\mathrm{p}}$ is chosen to facilitate comparison with variations in $A_{\mathrm{p}}$ (for which the same proportional range is used below) and is less than the likely uncertainty inherited from $\lambda_{\mathrm{q}}$, which is of order $(+50 \%,-33 \%)$ (IPCC, 2007b). The uncertainty in $T_{\mathrm{p}}\left(Q_{\mathrm{p}}\right)$ resulting from uncertainty in climate sensitivity is therefore greater than the range in Fig. 11.

Secondly, the CAF at time of peak temperature $\left(A_{\mathrm{p}}\right)$ captures the response of carbon partitioning between atmospheric, terrestrial and ocean carbon reservoirs to the accumulation of anthropogenic carbon in the earth system. It is well constrained parameter because of its integral character, which causes variability in the CAF to be much less than for the instantaneous AF (see Fig. 4 and associated discussion). The present (2005-2009) CAF is 0.42 , with a $5-95 \%$ uncertainty range of around $\pm 20 \%$, dominated by uncertainty in cumulative emissions, mostly from cumulative land use change. Some additional uncertainty in $A_{\mathrm{p}}$ arises from path dependence (see Fig. 9 and associated discussion). A variation of $A_{\mathrm{p}}$ in Fig. 11 of $(+25 \%,-20 \%)$ leads to a response in $T_{\mathrm{p}}\left(Q_{\mathrm{p}}\right)$ of about $(+0.5,-0.4) \mathrm{K}$ at $T_{\mathrm{p}}=2000 \mathrm{PgC}$.
This is less than the effect of a corresponding variation in $\lambda_{\mathrm{p}}$ because of the form of eq. (8), which causes $T_{\mathrm{p}}$ to respond more slowly than linearly to perturbations in $A_{\mathrm{p}}$ whereas the response to $\lambda_{\mathrm{p}}$ is linear.

Thirdly, the sensitivity of carbon pools to climate change $(\gamma)$ accounts for effects of climate change on $\mathrm{CO}_{2}$ fluxes, including releases of carbon from both currently mobile and currently largely immobile pools. In Fig. 11, we test additive variations in $\gamma$, taking $\gamma=0,40$ (reference) and $80 \mathrm{PgC} \mathrm{K}^{-1}$, a conservative estimate of the uncertainty range (Friedlingstein et al., 2006; Sitch et al., 2008). This leads to a response in $T_{\mathrm{p}}$ which grows with $Q_{\mathrm{p}}$ below $1000 \mathrm{PgC}$, and thereafter remains nearly constant (at about +0.6 and $-0.4 \mathrm{~K}$ for $\gamma=80$ and $0 \mathrm{PgC} \mathrm{K}^{-1}$, respectively) with further increase in $Q_{\mathrm{p}}$. This behaviour stems initially from the form of eq. (8), because both the gain $g$ and the amplification $1 /(1-g)$ decrease as $Q_{\mathrm{p}}$ increases. More fundamentally, it arises from the assumption in eq. (8) of a linear response of the carbon cycle to temperature.

The temperature response of the carbon cycle is highly uncertain for two reasons: first, processes determining the effects of climate on land and ocean carbon sinks are not well understood, as reflected in the high scatter in climate responses of carbon pools in models (Friedlingstein et al., 2006, Sitch et al., 2008). Secondly, there is still poor knowledge of the vulnerability of previously undisturbed carbon pools. A major potential pool is the organic carbon in frozen soils, estimated at nearly $1700 \mathrm{PgC}$ in total (Tarnocai et al., 2009), of which around $100 \mathrm{PgC}$ may be vulnerable to release by thawing over the next century (Schuur et al., 2009). There is also a significant pool of carbon in tropical peatland soils, mainly in the Southeast Asian archipelago, of which around $30 \mathrm{PgC}$ may be vulnerable to decomposition and fire following drainage (Hooijer et al., 2009). Net releases of carbon in other forest ecosystems are also likely through fire, insect attack and ecological transitions (Kurz et al., 2008a,b). If these uncertainties together cause the temperature response of the carbon cycle to be faster than linear, then $\gamma$ would increase with increasing $Q_{\mathrm{p}}$ and $T_{\mathrm{p}}$ would increase faster with $Q_{\mathrm{p}}$ than implied by eq. (8).

Finally, we assess non- $\mathrm{CO}_{2}$ radiative forcing at the time of peak temperature $\left(R_{\mathrm{Np}}\right)$. The reference value is $R_{\mathrm{Np}}=0$, implying no non- $\mathrm{CO}_{2}$ forcing. Figure 11 shows the effect of parameterizing $R_{\mathrm{Np}}$ in eq. (8) by using eq. (13) with $s_{\mathrm{N}}=0.00033$ and $0.00066 \mathrm{~W} \mathrm{~m}^{-2} \mathrm{PgC}^{-1}$, corresponding respectively to an additional 0.5 and $1 \mathrm{~W} \mathrm{~m}^{-2}$ of radiative forcing from the aggregate of all non- $\mathrm{CO}_{2}$ agents at $Q_{\mathrm{p}}=2000 \mathrm{PgC}$. These values lead respectively to increases in $T_{\mathrm{p}}$ of about 0.4 and $0.8 \mathrm{~K}$ at $Q_{\mathrm{p}}=$ $2000 \mathrm{PgC}$, and to higher increases at larger $Q_{\mathrm{p}}$. Non- $\mathrm{CO}_{2}$ contributions to warming of this order are consistent with more detailed calculations of the effects of non- $\mathrm{CO}_{2}$ forcing (Strassmann et al., 2009). The choice $s_{\mathrm{N}}=0.00033 \mathrm{~W} \mathrm{~m}^{-2} \mathrm{PgC}^{-1}$ approximately matches IPCC results for (T(2100), $Q(2100)$ ) (Fig. 10). 


\section{Conclusions}

This paper has offered three contributions. The first is an algebraic expression (eq. 8) for $T_{\mathrm{p}}\left(Q_{\mathrm{p}}\right)$, the peak warming $T_{\mathrm{p}}$ associated with a cumulative total anthropogenic $\mathrm{CO}_{2}$ emission $Q_{\mathrm{p}}$ to the time of peak warming. Given the definitions of its parameters, this expression is formally exact apart from a minor linearization with a typical error less than $1 \%$. With reference (best-estimate) parameter values and no non- $\mathrm{CO}_{2}$ radiative forcing, the expression is in good agreement with model results, including a non-linear box model for carbon-climate interactions (Appendix A) and also Allen et al. (2009). Equation (8) is robust for two reasons: first, it is based on a cumulative carbon budget parameterised by the CAF $A_{\mathrm{p}}$, a conservative quantity. Second, although two of its parameters $\left(A_{\mathrm{p}}\right.$ and $\left.\lambda_{\mathrm{p}}\right)$ are path dependent, the path dependencies act in opposite ways as $Q_{\mathrm{p}}$ varies.

The second contribution is an analytic form for smooth capped emissions trajectories with a single parameter $m$, the long-term mitigation rate at which emissions eventually decline. This form simultaneously satisfies the requirements of a specified all-time cumulative emission, smoothness and long-term exponential decline. Its purpose here is to test eq. (8) with a non-linear box model (Appendix A), but it is likely to have other applications.

The third contribution is an assessment of vulnerabilities in the carbon-climate-human system (in the sense of risks of harm from climate change), through the lens of eq. (8). Five different vulnerabilities correspond to quantities in this equation: (1) effects of increasing $\mathrm{CO}_{2}$ on the partition of anthropogenic carbon between atmospheric, land and ocean reservoirs (parameterised by $A_{\mathrm{p}}$, the CAF at time $t_{\mathrm{p}}$ of peak warming); (2) effects of climate change on $\mathrm{CO}_{2}$ fluxes (parameterized by $\gamma$, the aggregate sensitivity of land and ocean carbon to temperature change, including both currently mobile pools and currently immobile pools which are vulnerable to disturbance); (3) climate sensitivity (parameterised by $\lambda_{\mathrm{p}}$, the climate sensitivity at time $t_{\mathrm{p}}$ ); (4) changes in non- $\mathrm{CO}_{2}$ radiative forcing (parameterized by $R_{\mathrm{Np}}$, the net non- $\mathrm{CO}_{2}$ forcing at time $t_{\mathrm{p}}$ ); and (5) $\mathrm{CO}_{2}$ emissions pathways (parameterized by $\left.Q_{\mathrm{p}}\right)$. Two of these quantities $\left(R_{\mathrm{Np}}\right.$ and $Q_{\mathrm{p}}$ ) describe forcings by humans on the biophysical parts of the earth system, and the other three $\left(A_{\mathrm{p}}, \gamma\right.$ and $\left.\lambda_{\mathrm{p}}\right)$ describe biophysical processes and feedbacks. However, all contribute to vulnerability in the coupled carbon-climate-human system in the above sense.

Accounting for likely parameter variations and uncertainties, the largest vulnerability among the four parameters $\lambda_{\mathrm{p}}, A_{\mathrm{p}}, \gamma$ and $R_{\mathrm{Np}}$ resides with $\lambda_{\mathrm{p}}$, followed by $R_{\mathrm{Np}}$ and $\gamma$ and then by $A_{\mathrm{p}}$ (Figs 10 and 11). The dominance of $\lambda_{\mathrm{p}}$ arises because of the high uncertainty in the equilibrium climate sensitivity $\lambda_{\mathrm{q}}$, which is difficult to reduce because $\lambda_{\mathrm{q}}$ is strongly sensitive to small changes in positive feedbacks (Roe and Baker, 2007). However, arguably the largest vulnerability (risk of harm from climate change) in the coupled carbon-climate-human system is that associated with $Q_{\mathrm{p}}$, the quantity used as the primary independent variable in this analysis.

Finally, we note that eq. (8) is a conservative estimate of the relationship between cumulative emissions and peak warming because it is based on a model which cannot capture threshold crossings in the carbon-climate system. These are likely to become increasingly important at high warmings and cumulative emissions, raising the possibility that warmings and vulnerabilities are underestimated by eq. (8) at high cumulative emissions.

\section{Acknowledgments}

This paper is a contribution to the Global Carbon Project. MRR and JGC acknowledge with appreciation the support of the Department of Climate Change, Australian Government, which has supported the office of the Global Carbon Project in Canberra. We thank Ian Harman, John Finnigan and Ian Enting for comments on an early draft of this paper, two anonymous referees for detailed and extremely helpful comments, and Peter Briggs for assistance with figures.

\section{Appendix A: Non-linear box model for carbon-climate system}

The model state vector is

$\left(C_{\mathrm{A}}, C_{\mathrm{B} 1}, C_{\mathrm{B} 2}, C_{\mathrm{M} i},[\mathrm{X}]_{k}, \theta_{j}\right)$.

Its components are carbon masses $[\mathrm{PgC}]$ in the atmosphere $\left(C_{\mathrm{A}}\right)$, in fast and slow terrestrial biospheric $\mathrm{C}$ pools $\left(C_{\mathrm{B} 1}, C_{\mathrm{B} 2}\right)$, and in a set of marine (ocean) pools $\left(C_{\mathrm{M} i}\right)$; the atmospheric concentrations $[\mathrm{X}]_{k}$ of non- $\mathrm{CO}_{2}$ greenhouse gases, including $\mathrm{CH}_{4}$, $\mathrm{N}_{2} \mathrm{O}$, CFC-11 and CFC-12; and global perturbation temperature components $\left(\theta_{j}\right)$.

\section{Al Atmospheric $\mathrm{CO}_{2}$}

The mass balance for atmospheric $\mathrm{CO}_{2}\left(C_{A}\right)$ is

$\mathrm{d} C_{A} / \mathrm{d} t=F_{\mathrm{Foss}}+F_{\mathrm{LUC}}+F_{\mathrm{BA}}+F_{\mathrm{MA}}$,

where $F_{\text {Foss }}$ is the anthropogenic $\mathrm{CO}_{2}$ emission flux $\left[\mathrm{PgCyr}^{-1}\right]$ from fossil fuel combustion and other industrial processes including cement production, $F_{\text {LUC }}$ is the net anthropogenic emission flux from land use change, and $F_{\mathrm{BA}}$ and $F_{\mathrm{MA}}$ are the net $\mathrm{CO}_{2}$ fluxes to the atmosphere from the terrestrial biosphere and ocean. All fluxes are positive into the atmosphere. The atmospheric $\mathrm{CO}_{2}$ concentration is $\left[\mathrm{CO}_{2}\right]_{\mathrm{A}}=C_{\mathrm{A}} / r_{\mathrm{C}}$, where $r_{\mathrm{C}}=$ $2.13 \mathrm{PgC} \mathrm{ppm}^{-1}$. The forcing fluxes $F_{\text {Foss }}(t)$ and $F_{\mathrm{LUC}}(t)$ are externally prescribed, and $F_{\mathrm{BA}}$ and $F_{\mathrm{MA}}$ are specified functions of model state from phenomenological equations given in Table A1. 
Table A1. Phenomenological equations for quantities in the non-linear box model

\begin{tabular}{|c|c|c|}
\hline Quantity & Symbol & Phenomenological equation \\
\hline Terrestrial NPP & $F_{\mathrm{NPP}}[\mathrm{PgC} / \mathrm{yr}]$ & $F_{\mathrm{NPP}}\left(C_{\mathrm{A}}\right)=F_{\mathrm{NPP} 0}\left(1+\beta \ln \left(C_{\mathrm{A}} / C_{\mathrm{A} 0}\right)\right)$ \\
\hline Terrestrial respiration rate & $k_{\mathrm{B} i}\left[\mathrm{y}^{-1}\right]$ & $\ln \left(k_{\mathrm{B} i}\right)=\ln \left(k_{\mathrm{B} i(0)}\right)+\frac{T-T_{0}}{10} \ln \left(q_{10}\right)$ \\
\hline \multirow[t]{7}{*}{ Ocean-air $\mathrm{CO}_{2}$ flux } & $F_{\mathrm{MA}}[\mathrm{PgC} / \mathrm{yr}]$ & $\begin{array}{l}F_{\mathrm{MA}}=k_{\mathrm{Gas}} r_{\mathrm{C}}\left(\left[\mathrm{CO}_{2}\right]_{\mathrm{m}}-\left[\mathrm{CO}_{2}\right]_{\mathrm{A}}\right) \\
\text { where }\left[\mathrm{CO}_{2}\right]_{\mathrm{m}} \text { and }\left[\mathrm{CO}_{2}\right]_{\mathrm{A}}=C_{\mathrm{A}} / r_{\mathrm{C}} \text { are ocean mixed-layer and atmospheric } p \mathrm{CO}_{2}[\mathrm{ppm}] . \\
{\left[\mathrm{CO}_{2}\right]_{\mathrm{m}} \text { is given by }\left(\mathrm{Joos}_{\text {et al., }} 1996\right) \text { : }}\end{array}$ \\
\hline & & {$\left[\mathrm{CO}_{2}\right]_{\mathrm{m}}(\mathrm{DIC}, T)=\left[\mathrm{CO}_{2}\right]_{\mathrm{M} 0}+\frac{\operatorname{dic} \times z_{a}(T)}{1-\operatorname{dic} \times z_{b}(T)}$} \\
\hline & & $z_{a}(T)=975.61\left(1.7561-0.031618 T+0.0004444 T^{2}\right)$ \\
\hline & & $z_{b}(T)=975.61\left(0.004096-7.7086 \times 10^{-5} T+6.10 \times 10^{-7} T^{2}\right)$ \\
\hline & & $\begin{array}{l}\text { where } \mathrm{DIC}=\mathrm{DIC}_{0}+\text { dic is the dissolved inorganic carbon }\left[\mathrm{molC} \mathrm{m}^{-3}\right] \text { in the ocean mixed } \\
\text { layer, } \mathrm{DIC} \mathrm{I}_{0} \text { is its pre-industrial equilibrium value, dic is the perturbation part of DIC, and } \\
{\left[\mathrm{CO}_{2}\right]_{M 0}=280 \mathrm{ppm} \text {. DIC is proportional to the ocean mixed-layer carbon store [PgC], with }} \\
\text { perturbation part } c_{\mathrm{m}}=\sum c_{M i} \text { given by the sum of the stores } c_{M i} \text { determined by eq. (A5). } \\
\text { This relationship is }\end{array}$ \\
\hline & & $\operatorname{dic}\left(c_{\mathrm{m}}\right)=\left(10^{15} c_{\mathrm{m}}\right) /\left(A_{\mathrm{m}} h_{\mathrm{m}} M_{\mathrm{C}}\right) \quad\left[\mathrm{molC} \mathrm{m}{ }^{-3}\right]$ \\
\hline & & $\begin{array}{l}\text { where } A_{\mathrm{m}} \text { is the ocean surface area, } h_{\mathrm{m}} \text { the ocean mixed-layer depth, and } M_{C} \text { the atomic } \\
\text { mass of } \mathrm{C} \text {. }\end{array}$ \\
\hline
\end{tabular}

Note: Notation is defined in Table A2.

\section{A2 Terrestrial biospheric carbon}

The terrestrial biospheric carbon stores $C_{\mathrm{B} 1}$ and $C_{\mathrm{B} 2}$ are the total carbon stores $[\mathrm{PgC}]$ in notional global 'grass' and 'forest' biomes, respectively (combining biomass and soil carbon, which are not separated in this model). The governing mass balance equations are

$\mathrm{d} C_{\mathrm{B} 1} / \mathrm{d} t=a_{\mathrm{B} 1} F_{\mathrm{NPP}}-k_{1} C_{B 1}$,

$\mathrm{d} C_{\mathrm{B} 2} / \mathrm{d} t=a_{B 2} F_{\mathrm{NPP}}-k_{1} C_{\mathrm{B} 2}-F_{\mathrm{LUC}}$,

where $F_{\mathrm{NPP}}$ is the global terrestrial net primary production (NPP) of biomass carbon $\left[\mathrm{PgC}^{-1}\right], k_{\mathrm{B} i}$ is the turnover rate for heterotrophic respiration $\left[\mathrm{y}^{-1}\right]$ from biomass store $i$, and $a_{\mathrm{B} i}$ is the fraction of global NPP entering biomass store $i$, with $a_{\mathrm{B} 1}+a_{\mathrm{B} 2}=$ 1. The NPP is a function of $\left[\mathrm{CO}_{2}\right]_{\mathrm{A}}$ through phenomenological equations (Table $\mathrm{A} 1$ ), and the turnover rates $k_{\mathrm{B} i}$ depend on the global temperature $T_{\mathrm{A}}$ (Table A1). The net land use change flux $F_{\mathrm{LUC}}$ is withdrawn from the forest carbon store $C_{B 2}$. The biosphere-atmosphere exchange flux $F_{\mathrm{BA}}$ (positive into the atmosphere) is the negative terrestrial net ecosystem productivity (NEP):

$$
F_{\mathrm{BA}}=-F_{\mathrm{NEP}}=-\left(F_{\mathrm{NPP}}-k_{1} C_{\mathrm{B} 1}-k_{2} C_{\mathrm{B} 2}\right) .
$$

\section{A3 Ocean carbon}

Carbon in the ocean mixed layer (as dissolved inorganic carbon, DIC) is the sum of several stores with different turnover rates $k_{C i}$ for exchange with the deep ocean. The mass balances for these stores are

$\frac{\mathrm{d} c_{\mathrm{M} i}}{\mathrm{~d} t}=-a_{\mathrm{C} i} F_{\mathrm{MA}}-k_{\mathrm{C} i} c_{\mathrm{M} i} ; \quad c_{\mathrm{M} i}(0)=0$,

where $c_{\mathrm{M} i}(t)=C_{\mathrm{M} i}(t)-C_{\mathrm{M} i 0}[\mathrm{PgC}]$ is the perturbation of marine $\mathrm{C}$ store $i$ from its pre-industrial equilibrium state $C_{\mathrm{M} i 0}$, and $a_{\mathrm{C} i}$ is the fraction of the atmosphere-ocean $\mathrm{CO}_{2}$ flux entering store $i$ (with $\sum a_{\mathrm{C} i}=1$ ). The ocean-atmosphere flux $F_{\mathrm{MA}}$ (positive into the atmosphere) is a function of $T_{\mathrm{A}}$ and $c_{\mathrm{M} i}$ (as DIC) through phenomenological equations (Table A1). Equation (A5) is equivalent to a pulse response function $\sum a_{\mathrm{C} i} \exp \left(-k_{\mathrm{C} i} t\right)$ for DIC in the ocean mixed layer (Appendix B). The weights $a_{\mathrm{C} i}$ and rates $k_{\mathrm{C} i}$ are specified using pulse response functions for scalar transfer from the mixed layer to the deep ocean from advanced ocean models, thus capturing the ocean dynamics represented in these models. The values of $a_{\mathrm{C} i}$ and $k_{\mathrm{C} i}$ used here (Table A2) are from a four-term fit to the average of the pulse response functions of the HILDA and Box-Diffusion models (Joos et al., 1996), which are in good agreement. 
Table A2. Values for parameters in the nonlinear box model

\begin{tabular}{|c|c|c|c|}
\hline Parameter & Symbol & Units & Value \\
\hline \multicolumn{4}{|l|}{ Physical constants } \\
\hline \multicolumn{4}{|l|}{ Mass/concentration ratios } \\
\hline $\mathrm{C}$ in atmospheric $\mathrm{CO}_{2}$ & $r_{C}$ & $\mathrm{PgC} \mathrm{ppm}^{-1}$ & 2.130 \\
\hline Atmospheric $\mathrm{CH}_{4}$ & $r_{\mathrm{CH}_{4}}$ & $\mathrm{TgCH}_{4} \mathrm{ppb}^{-1}$ & 2.845 \\
\hline Atmospheric $\mathrm{N}_{2} \mathrm{O}$ & $r_{\mathrm{N}_{2} \mathrm{O}}$ & $\mathrm{TgN}_{2} \mathrm{Oppb} b^{-1}$ & 7.804 \\
\hline Atmospheric CFC-11 & $r_{\mathrm{CFC11}}$ & $\mathrm{TgCFC} 11 \mathrm{ppb}^{-1}$ & 24.36 \\
\hline Atmospheric CFC-12 & $r_{\mathrm{CFC} 12}$ & $\mathrm{TgCFC} 12 \mathrm{ppb}^{-1}$ & 21.44 \\
\hline Atomic mass of $\mathrm{C}$ & $M_{\mathrm{C}}$ & $\mathrm{gC} \mathrm{mol}^{-1}$ & 12.0107 \\
\hline Earth radius & $r_{\mathrm{E}}$ & $\mathrm{m}$ & $6.37 \times 10^{6}$ \\
\hline \multicolumn{4}{|l|}{ Terrestrial C parameters } \\
\hline Pre-industrial terrestrial NPP & $F_{\mathrm{NPP} 0}$ & $\mathrm{PgCy}^{-1}$ & 40 \\
\hline Parameter in NPP formulation & $\beta$ & & 0.8 \\
\hline NPP partition fraction for $C_{B 1}$ & $a_{\mathrm{B} 1}$ & & 0.8 \\
\hline \multicolumn{4}{|l|}{ Pre-industrial turnover rates: } \\
\hline$C_{\mathrm{B} 1}$ pool & $k_{\mathrm{B} 1(0)}$ & $\mathrm{yr}^{-1}$ & $1 / 3$ \\
\hline$C_{\mathrm{B} 2}$ pool & $k_{\mathrm{B} 2(0)}$ & $\mathrm{yr}^{-1}$ & $1 / 300$ \\
\hline$q_{1} 0$ for terrestrial respiration & $q_{1} 0$ & & 2.0 \\
\hline \multicolumn{4}{|l|}{ Ocean C parameters } \\
\hline Air-ocean gas exchange rate & $k_{\mathrm{Gas}}$ & $\mathrm{yr}^{-1}$ & $1 / 8.76$ \\
\hline Ocean area & $A_{\mathrm{m}}$ & $\mathrm{m}^{2}$ & $0.7 \times 4 \pi r_{\mathrm{E}}^{2}$ \\
\hline Ocean mixed-layer depth & $h_{\mathrm{m}}$ & $\mathrm{m}$ & 75 \\
\hline Weights in PRF for ocean $\mathrm{CO}_{2}$ & $a_{\mathrm{C} i}$ & & $0.512934,0.320278,0.142183,0.0246045$ \\
\hline Rates in PRF for ocean $\mathrm{CO}_{2}$ & $k_{\mathrm{C} i}$ & $\mathrm{yr}^{-1}$ & $5.22893,0.356532,0.0194692,0.0$ \\
\hline \multicolumn{4}{|l|}{ Pre-industrial C stores } \\
\hline DIC & $\mathrm{DIC}_{0}$ & $\mathrm{molC} \mathrm{m}^{-3}$ & 2.089 \\
\hline Global temperature & $T_{0}$ & degrees $\mathrm{C}$ & 15 \\
\hline Atmospheric $\left[\mathrm{CO}_{2}\right]$ & {$\left[\mathrm{CO}_{2}\right]_{0}$} & ppm & 280 \\
\hline Atmospheric $\mathrm{CO}_{2}$ store & $C_{A 0}$ & $\mathrm{PgC}$ & $r_{C}\left[\mathrm{CO}_{2}\right]_{0}$ \\
\hline Terrestrial C stores & $C_{B i(0)}$ & $\mathrm{PgC}$ & $a_{B i} F_{\mathrm{NPP} 0} / k_{B i(0)}$ \\
\hline \multicolumn{4}{|l|}{ Pre-industrial non- $\mathrm{CO}_{2}$ concentrations } \\
\hline $\mathrm{CH}_{4}$ & {$\left[\mathrm{CH}_{4}\right]_{0}$} & $\mathrm{ppb}$ & 700 \\
\hline $\mathrm{N}_{2} \mathrm{O}$ & {$\left[\mathrm{N}_{2} \mathrm{O}\right]_{0}$} & $\mathrm{ppb}$ & 270 \\
\hline CFC-11, CFC-12 & {$[\mathrm{CFC}]_{0}$} & $\mathrm{ppb}$ & 0 \\
\hline \multicolumn{4}{|l|}{ Decay rates for non- $\mathrm{CO}_{2}$ gases } \\
\hline $\mathrm{CH}_{4}$ & $k_{\mathrm{CH}_{4}}$ & $\mathrm{yr}^{-1}$ & $8.2^{-1}\left(\left[\mathrm{CH}_{4}\right] /\left[\mathrm{CH}_{4}\right]_{0}\right)^{-0.12}$ \\
\hline $\mathrm{N}_{2} \mathrm{O}$ & $k_{\mathrm{N}_{2} \mathrm{O}}$ & $\mathrm{yr}^{-1}$ & $1 / 114$ \\
\hline CFC-11 & $k_{\mathrm{CFC} 11}$ & $\mathrm{yr}^{-1}$ & $1 / 45$ \\
\hline CFC-12 & $k_{\mathrm{CFC12}}$ & $\mathrm{yr}^{-1}$ & $1 / 100$ \\
\hline \multicolumn{4}{|l|}{ Climate properties } \\
\hline Weights in SRF for climate & $b_{\mathrm{T} i}$ & & $0.434,0.175,0.391$ \\
\hline Rates SRF for climate & $k_{\mathrm{T} i}$ & $\mathrm{yr}^{-1}$ & $4.51^{-1}, 140.4^{-1}, 1476^{-1}$ \\
\hline Equilibrium climate sensitivity & $\lambda_{\mathrm{q}}$ & $\mathrm{KW}^{-1} \mathrm{~m}^{2}$ & 1.235 \\
\hline Coefficient for aerosol forcing & $c_{\text {Aero }}$ & $\mathrm{W} \mathrm{m}^{-2} \mathrm{PgC}^{-1} \mathrm{y}$ & 0.12 \\
\hline
\end{tabular}

\section{A4 Global temperature}

The absolute global temperature is $T_{\mathrm{A}}(t)=T_{\mathrm{A} 0}+T(t)$, where $T_{\mathrm{A} 0}$ is the initial (pre-industrial) temperature and $T(t)$ is the temperature perturbation. This is written as $T(t)=\sum \theta_{j}(t)[\mathrm{K}]$, with components $\theta_{j}(t)$ satisfying

$$
\frac{\mathrm{d} \theta_{j}}{\mathrm{~d} t}=k_{\mathrm{T} j} b_{\mathrm{T} j} \lambda_{\mathrm{q}} R(t)-k_{\mathrm{T} j} \theta_{j} ; \quad \theta_{j}(0)=0
$$


with radiative forcing $R(t)$. The weights $b_{\mathrm{T} j}$ and rates $k_{\mathrm{T} j}$ characterize the climate step response function $1-\sum b_{\mathrm{T} j} \exp \left(-k_{\mathrm{T} j} t\right)$ (Appendix B). Here we use a three-term function with coefficients (Table A2) derived by inverting the Laplace transform of the climate response function for the HadCM3 model (Li and Jarvis, 2009).

\section{A5 Radiative forcing}

Radiative forcing is taken to be the sum of contributions from anthropogenic greenhouse gases, together with aerosols:

$R(t)=R_{\mathrm{CO}_{2}}\left(\left[\mathrm{CO}_{2}\right]\right)+R_{\mathrm{CH}_{4}}\left(\left[\mathrm{CH}_{4}\right]\right)+\cdots+R_{\text {Aero }}$.

The gases considered are $\mathrm{CO}_{2}, \mathrm{CH}_{4}, \mathrm{~N}_{2} \mathrm{O}$ and halocarbons (represented only by $\mathrm{CFC}-11$ and $\mathrm{CFC}-12$ ). We use conventional expressions for radiative forcing as a function of gas concentration (IPCC, 2001b, p. 358), specifically eq. (5) for $\mathrm{CO}_{2}$. The (negative) aerosol forcing is modelled as proportional to total $\mathrm{CO}_{2}$ emissions,

$R_{\text {Aero }}(t)=-c_{\text {Aero }}\left(F_{\text {Foss }}(t)+F_{\text {LUC }}(t)\right)$

This assumes proportional relationships between aerosol radiative forcing, aerosol concentrations, aerosol emissions (taking the aerosol turnover rate to be rapid) and fossil fuel emissions. The proportionality coefficient $c_{\text {Aero }}$ is chosen so that eq. (A7) yields a total radiative forcing of $+1.6 \mathrm{~W} \mathrm{~m}^{-2}$ in 2005 (IPCC, 2007b). This coefficient has different units from $s_{\mathrm{N}}$ in eq. (13).

\section{A6 Non- $\mathrm{CO}_{2}$ greenhouse gases}

Concentrations for gas $X\left(\mathrm{CH}_{4}, \mathrm{~N}_{2} \mathrm{O}\right.$ or CFCs $)$ are modelled as

$$
\frac{\mathrm{d}[\mathrm{X}]}{\mathrm{d} t}=r_{\mathrm{X}}^{-1}\left(F_{\mathrm{X}(\mathrm{Nat})}+F_{\mathrm{X}(\mathrm{Anth})}(t)\right)-k_{\mathrm{X}}[\mathrm{X}]
$$

with mass-concentration ratios $r$, fluxes $F$ (separating natural and anthropogenic components) and atmospheric decay rates $k$. The assumed decay rates for $\mathrm{N}_{2} \mathrm{O}$ and CFCs are constant, while that for $\mathrm{CH}_{4}$ is a weak function of $\mathrm{CH}_{4}$ concentration (Table A1) to account for the known decrease in the $\mathrm{CH}_{4}$ decay rate from pre-industrial times to the present (Prinn, 2004). The natural fluxes $F_{(\mathrm{Nat})}$ are taken as time-independent and set to match pre-industrial concentrations in the assumed preindustrial equilibrium state. Past anthropogenic $\mathrm{CH}_{4}$ fluxes are prescribed from data (Stern and Kaufmann, 1996), and past anthropogenic $\mathrm{N}_{2} \mathrm{O}$ and $\mathrm{CFC}$ fluxes are prescribed as exponential functions of time. For the present illustrative calculations, future $\mathrm{CH}_{4}$ and $\mathrm{N}_{2} \mathrm{O}$ emissions are taken from the IPCC SRES A1B marker scenario (Nakicenovic et al., 2000) with linear extrapolation from 2100 to 2300, assuming a return to present (2000) emissions in 2300, and future halocarbon emissions are assumed constant at 2000 values.

\section{Appendix B: Linear systems and response functions}

\section{B1 Pulse and step response functions}

For a linear system with an equilibrium steady state in response to steady forcing, the forcing $f(t)$ and the response $x(t)$ (with initial condition $x(0)=0$ ) are related by the alternative integral expressions

$x(t)=\int_{0}^{t} f(\tau) g(t-\tau) \mathrm{d} \tau$,

$x(t)=\Lambda_{\mathrm{q}} \int_{0}^{t} f^{\prime}(\tau) h(t-\tau) \mathrm{d} \tau$,

where $g(t)$ is the Green's function or pulse response function (PRF), $h(t)$ is the step response function (SRF), $\Lambda_{\mathrm{q}}$ is an equilibrium system sensitivity with the dimension of time, and a prime denotes differentiation in time $\left(x^{\prime}(t)=\mathrm{d} x / \mathrm{d} t\right)$. The PRF is the response to a unit pulse or spike forcing at $t=0$, and the SRF is the realized fraction at time $t$ of the equilibrium response $\Lambda_{\mathrm{q}}$ to a unit step forcing $(f(t)=0$ when $t<0$ and $f(t)=1$ when $t \geq 0$ ). The relationship between the PRF and the SRF is

$g(t)=\Lambda_{\mathrm{q}} h^{\prime}(t)$.

Requirements on $g(t)$ and $h(t)$ are $g(0)=1, h(0)=0$, and (assuming that the equilibrium state exists) $g(t) \rightarrow 0$ and $h(t) \rightarrow$ 1 as $t \rightarrow \infty$. The PRF form is widely used in carbon cycle science and the SRF form in climate science, as for example in eq. (1).

\section{B2 Systems with exponential response functions}

Let the response functions $g(t)$ and $h(t)$ be sums of decaying exponential terms:

$g(t)=\sum_{i} a_{i} \exp \left(-k_{i} t\right)$

$h(t)=1-\sum_{i} b_{i} \exp \left(-k_{i} t\right)$

with rates $k_{i}$ and weights $a_{i}$ for the PRF and $b_{i}$ for the SRF. These rates must sum to $1\left(\sum a_{i}=1\right.$ and $\left.\sum b_{i}=1\right)$. The relationships between $a_{i}$ and $b_{i}$ are

$b_{i}=\frac{a_{i}}{k_{i} \tau_{\mathrm{q}}} ; \quad a_{i}=b_{i} k_{i} \tau_{\mathrm{q}}$,

where $\tau_{\mathrm{q}}$ is the integral time scale of the PRF,

$\tau_{\mathrm{q}}=\int_{0}^{\infty} g(\tau) \mathrm{d} \tau=\sum_{i} \frac{a_{i}}{k_{i}}=\frac{1}{\sum_{i} b_{i} k_{i}}$.

If and only if $g(t)$ and $h(t)$ respectively take the forms of eqs. (B4) and (B5), the system response $x(t)$ is a sum of terms 
$x_{i}(t)$ which satisfy independent differential equations:

$$
\begin{aligned}
\frac{\mathrm{d} x_{i}}{\mathrm{~d} t} & =a_{i} f(t)-k_{i} x_{i}(t) \\
& =b_{i} k_{i} \tau_{\mathrm{q}} f(t)-k_{i} x_{i}(t)
\end{aligned}
$$

with initial conditions $x_{i}(0)=0$.

With steady forcing $f_{\mathrm{q}}$, the long-term equilibrium state (denoted by a subscript q) satisfies $\mathrm{d} x_{i} / \mathrm{d} t=0$ for all components $i$, so that

$x_{\mathrm{q} i}=\frac{a_{i} f_{\mathrm{q}}}{k_{i}} ; \quad x_{\mathrm{q}}=\sum_{i} x_{\mathrm{q} i}=\tau_{\mathrm{q}} f_{\mathrm{q}}$.

\section{B3 System sensitivity}

A measure of the sensitivity of the system at time $t$ is the instantaneous ratio of response to forcing, $\Lambda(t)=x(t) / f(t)$, with the dimension of time. The long-term equilibrium sensitivity with steady forcing $f_{\mathrm{q}}$ is $\Lambda_{\mathrm{q}}=x_{\mathrm{q}} / f_{\mathrm{q}}$ (eq. B2). eq. (B10) yields two forms for $\Lambda_{\mathrm{q}}$ :

$\Lambda_{\mathrm{q}}=\tau_{\mathrm{q}} \quad$ and $\quad \Lambda_{\mathrm{q}}=\frac{\sum x_{\mathrm{q} i}}{\sum k_{i} x_{\mathrm{q} i}}$.

Assuming the solution $x(t)$ has a peak value (more generally, a local extremum) at time $t_{\mathrm{p}}$, we can also find the peak sensitivity $\Lambda_{\mathrm{p}}=x_{\mathrm{p}} / f_{\mathrm{p}}$, where $x_{\mathrm{p}}=x\left(t_{\mathrm{p}}\right)$ and $f_{\mathrm{p}}=f\left(t_{\mathrm{p}}\right)$. At the time $t_{\mathrm{p}}$ we have $\mathrm{d} x / \mathrm{d} t=\sum \mathrm{d} x_{i} / \mathrm{d} t=0$. Summing eq. (B8) over $i$ and equating to zero, this yields

$\Lambda_{\mathrm{p}}=\frac{\sum x_{\mathrm{p} i}}{\sum k_{i} x_{\mathrm{p} i}}$

Eqs. (B11) and (B12) show that the sensitivities $\Lambda$ at long-term equilibrium and at the peak time $t_{\mathrm{p}}$ are both given by weighted parallel averages of the component time scales $k_{i}^{-1}$, where the weights are the component stores $x_{i}$ at the relevant times. In both cases, this is true because of the constraint $\sum \mathrm{d} x_{i} / \mathrm{d} t=0$. At long-term equilibrium, but not at the peak time $t_{\mathrm{p}}$, the system also satisfies the stronger constraint $\mathrm{d} x_{i} / \mathrm{d} t=0$ for each component $i$. For systems with a finite $\tau_{\mathrm{q}}$ the equilibrium sensitivity $\Lambda_{\mathrm{q}}$ is path-independent, but the peak sensitivity $\Lambda_{\mathrm{p}}$ depends on the forcing path $f(t)$ which yields the peak $x_{\mathrm{p}}$.

\section{B4 Response functions and sensitivities for global temperature}

For global temperature, the SRF expression is eq. (1). Also writing the PRF form using eq. (B1), this is

$$
\begin{aligned}
T(t) & =\frac{1}{H} \int_{0}^{t} R(\tau) g_{\mathrm{T}}(t-\tau) \mathrm{d} \tau \\
& =\lambda_{\mathrm{q}} \int_{0}^{t} R^{\prime}(\tau) h_{\mathrm{T}}(t-\tau) \mathrm{d} \tau,
\end{aligned}
$$

where $T(t)$ is the global temperature perturbation $[\mathrm{K}], R(t)$ is the radiative forcing $\left[\mathrm{W} \mathrm{m} \mathrm{m}^{-2}\right], H$ is an average heat capacity for the thermal stores which interact with climate $\left[\mathrm{J} \mathrm{m}^{-2} \mathrm{~K}^{-1}\right]$, $g_{\mathrm{T}}(t)$ and $h_{\mathrm{T}}(t)$ are respectively the PRF and SRF for climate, and $\lambda_{\mathrm{q}}$ is the equilibrium climate sensitivity $\left[\mathrm{KW}^{-1} \mathrm{~m}^{2}\right]$. The equilibrium and peak climate sensitivities $\lambda_{\mathrm{q}}$ and $\lambda_{\mathrm{p}}$ are related to $H$ and the response function by

$\lambda_{\mathrm{q}}=\Lambda_{\mathrm{q}} / H=\tau_{\mathrm{q}} / H ; \quad \lambda_{\mathrm{p}}=\Lambda_{\mathrm{p}} / H$,

where $\Lambda_{\mathrm{q}}$ and $\Lambda_{\mathrm{p}}$ are sensitivities with the dimension of time given by eqs. (B11) and (B12), and $\tau_{\mathrm{q}}$ is given by eq. (B7) in terms of coefficients in an exponential response function.

\section{Appendix C: Data sources}

Data on past $\mathrm{CO}_{2}$ emissions from fossil fuels and other industrial processes (mainly cement production) are from the Carbon Dioxide Information and Analysis Center (CDIAC), US Department of Energy (Boden et al., 2009).

Data on past $\mathrm{CO}_{2}$ emissions from land use change are from Houghton (2003), updated by the Global Carbon Project (Le Quere et al., 2009).

Data for $\mathrm{CO}_{2}$ concentrations are the average of annual-mean concentrations at Mauna Loa and the South Pole, from the Scripps Institution of Oceanography (Keeling et al., 2001, 2005).

Temperature data are annual global temperatures from the Climatic Research Unit, University of East Anglia (http://www.cru.uea.ac.uk/cru/data/temperature/).

Annual time series for the $\mathrm{AF}$ and $\mathrm{CAF}$ were inferred from the above data on $\mathrm{CO}_{2}$ emissions and concentrations, using the definitions of the AF and CAF (Raupach et al., 2008).

\section{References}

Allen, M. R., Frame, D. J., Huntingford, C., Jones, C. D., Lowe, J. A. and co-authors. 2009. Warming caused by cumulative carbon emissions: towards the trillionth tonne. Nature 458, 1163-1166.

Boden, T. A., Marland, G. and Andres, R. J. 2009. Global, Regional, and National Fossil-Fuel $\mathrm{CO}_{2}$ Emissions, Carbon Dioxide Information Analysis Center, Oak Ridge National Laboratory, U.S. Department of Energy, Oak Ridge, TN, USA.

Canadell, J. G., Le Quere, C., Raupach, M. R., Field, C. B., Buitenhuis E. T. and co-authors. 2007. Contributions to accelerating atmospheric $\mathrm{CO}_{2}$ growth from economic activity, carbon intensity, and efficiency of natural sinks. Proc. Natl. Acad. Sci. USA 104, 18866-18870.

Cox, P. M., Betts, R. A., Jones, C. D., Spall, S. A. and Totterdell, I. J. 2000. Acceleration of global warming due to carbon-cycle feedbacks in a coupled climate model. Nature 408, 184-187.

Den Elzen, M. G. J., Berk, M., Schaeffer, M., Olivier, J. G. J., Hendriks, C. and Metz, B. 1999. The Brazilian proposal and other options for international burden sharing: an evaluation of methodological and policy aspects using the FAIR model. Report No. 72801011, National Institute of Publoic Health and the Environment, Bilthoven, The Netherlands. 
Frame, D. J., Stone, D. A., Stott, P. A. and Allen, M. R. 2006. Alternatives to stabilization scenarios. Geophys. Res. Lett. 33, doi:10.1029/2006GL025801.

Friedlingstein, P., Cox, P., Betts, R., Bopp, L., von Bloh, W. and coauthors. 2006. Climate-carbon cycle feedback analysis: results from the C4MIP model intercomparison. J. Clim. 19, 3337-3353.

Gruber, N., Friedlingstein, P., Field, C. B., Valentini, R., Heimann, M. and co-authors. 2004. The vulnerability of the carbon cycle in the 21st century: an assessment of carbon-climate-human interactions. In: The Global Carbon Cycle: Integrating Humans, Climate, and the Natural World, (eds. C. B. Field and M. R. Raupach), Island Press, Washington, 45-76.

Hansen, J. E., Sato, M., Kharecha, P., Beerling, D. J., Masson-Delmotte V. and co-authors. 2008. Target atmospheric $\mathrm{CO}_{2}$ : where should humanity aim?. Open Atmos. Sci. J. 2, 217-231.

Hooijer, A., Page, S., Canadell, J. G., Silvius, M., Kwadijk, J. and co-authors. 2009. Current and future $\mathrm{CO}_{2}$ emissions from drained peatlands in Southeast Asia. Biogeosci. Discuss. 6, 7207-7230.

Houghton, R. A. 2003. Revised estimates of the annual net flux of carbon to the atmosphere from changes in land use and land management 1850-2000. Tellus 55B, 378-390.

IPCC 2001a. Climate Change 2001: Impacts, Adaptation, and Vulnerability. Contribution of Working Group II to the Third Assessment Report of the Intergovernmental Panel on Climate Change, Cambridge University Press, Cambridge, UK.

IPCC 2001b. Climate Change 2001: The Scientific Basis. Contribution of Working Group I to the Third Assessment Report of the Intergovernmental Panel on Climate Change, Cambridge University Press, Cambridge, United Kingdom and New York.

IPCC 2007a. Climate Change 2007: Impacts, Adaptation and Vulnerability. Contribution of Working Group II to the Fourth Assessment Report of the Intergovernmental Panel on Climate Change. Cambridge University Press, Cambridge, UK and New York, NY, USA, $976 \mathrm{pp}$.

IPCC 2007b. Climate Change 2007: The Physical Science Basis. Contribution of Working Group I to the Fourth Assessment Report of the Intergovernmental Panel on Climate Change. Cambridge University Press, Cambridge, UK and New York, NY, USA, 996 pp.

Joos, F., Bruno, M., Fink, R., Siegenthaler, U., Stocker, T. F. and coauthors. 1996. An efficient and accurate representation of complex oceanic and biospheric models of anthropogenic carbon uptake. Tellus Series B-Chem. Phys. Meteorol. 48, 397-417.

Keeling, C. D., Piper, S. C., Bacastow, R. B., Wahlen, M., Whorf, T. P. and co-authors. 2001. Exchanges of atmospheric $\mathrm{CO}_{2}$ and ${ }^{13} \mathrm{CO}_{2}$ with the terrestrial biosphere and oceans from 1978 to 2000. I. Global Aspects, SIO Reference Series, No. 01-06, Scripps Institution of Oceanography, San Diego.

Keeling, C. D., Piper, S. C., Bacastow, R. B., Wahlen, M., Whorf, T. P. and co-authors. 2005. Atmospheric $\mathrm{CO}_{2}$ and ${ }^{13} \mathrm{CO}_{2}$ exchange with the terrestrial biosphere and oceans from 1978 to 2000: observations and carbon cycle implications. In: A History of Atmospheric $\mathrm{CO}_{2}$ and its effects on Plants, Animals, and Ecosystems, (eds. J. R. Ehleringer, T. E. Cerling and M. D. Dearing), Springer Verlag, New York, 83113.

Knutti, R. and Hegerl, G. C. 2008. The equilibrium sensitivity of the Earth's temperature to radiation changes. Nat. Geosci. 1, 735743.
Kurz, W. A., Dymond, C. C., Stinson, G., Rampley, G. J., Neilson, E. T. and co-authors. 2008a. Mountain pine beetle and forest carbon feedback to climate change. Nature 452, 987-990.

Kurz, W. A., Stinson, G., Rampley, G. J., Dymond, C. C. and Neilson, E. T. 2008b. Risk of natural disturbances makes future contribution of Canada's forests to the global carbon cycle highly uncertain. Proc. Natl. Acad. Sci. USA 105, 1551-1555.

Le Quere, C., Raupach, M. R., Canadell, J. G., Marland, G., Bopp, L. and co-authors. 2009. Trends in the sources and sinks of carbon dioxide. Nat. Geosci. 2, doi:10.1038/NGEO689.

Li, S. and Jarvis, A. 2009. Long run surface temperature dynamics of an A-OGCM: the HadCM3 $4 \mathrm{xCO}_{2}$ forcing experiment revisited. Clim. Dyn. 33, 817-825.

Li, S., Jarvis, A. J. and Leedal, D. T. 2009. Are response function representations of the global carbon cycle ever interpretable? Tellus 61B, 361-371.

Lowe, J. A., Huntingford, C., Raper, S. C. B., Jones, C. D., Liddicoat, S. $\mathrm{K}$. and co-authors. 2009. How difficult is it to recover from dangerous levels of global warming? Environ. Res. Lett. 4, doi:10.1088/17489326/4/1/014012.

Matthews, H. D., Gillett, N. P., Stott, P. A. and Zickfeld, K. 2009. The proportionality of global warming to cumulative carbon emissions. Nature 459, 829-833.

Meinshausen, M. 2006. What does a 2C target mean for greenhouse gas concentrations? A brief analysis based on multi-gas emission pathways and several climate sensitivity uncertainty estimates. In: Avoiding Dangerous Climate Change, (eds. H. J. Schellnhuber, W. Cramer, N. Nakicenovic, T. M. L. Wigley and G. Yohe), Cambridge University Press, Cambridge, 265-279.

Meinshausen, M., Meinshausen, N., Hare, W., Raper, S. C. B., Frieler, $\mathrm{K}$. and co-authors. 2009. Greenhouse gas emission targets for limiting global warming to $2^{\circ} \mathrm{C}$. Nature $\mathbf{4 5 8}, 1158-1162$.

Myhre, G., Highwood, E. J., Shine, K. P. and Stordal, F. 1998. New estimates of radiative forcing due to well mixed greenhouse gases. Geophys. Res. Lett. 25, 2715-2718.

Nakicenovic, N., Alcamo, J., Davis, G., de Vries, B., Fenhann, J. and co-authors. 2000. IPCC Special Report on Emissions Scenarios. Cambridge University Press, Cambridge, U.K. and New York, 599 pp.

Oeschger, H., Siegenthaler, U., Schotterer, U. and Gugelmann, A. 1975. Box diffusion-model to study carbon-dioxide exchange in nature. Tellus 27, 168-192.

Prinn, R. G. 2004. Non- $\mathrm{CO}_{2}$ greenhouse gases. In: The Global Carbon Cycle: Integrating Humans, Climate, and the Natural World, (eds. C. B. Field and M. R. Raupach), Island Press, Washington, 205216.

Ramanathan, V. and Feng, Y. 2008. On avoiding dangerous anthropogenic interference with the climate system: formidable challenges ahead. Proc. Natl. Acad. Sci. USA 105, 14245-14250.

Raupach, M. R. and Canadell, J. G. 2010. Carbon and the anthropocene. Curr. Opin. Environ. Sustainabil. 4, doi:10.1016/ j.cosust.2010.04.003.

Raupach, M. R., Canadell, J. G. and Le Quere, C. 2008. Anthropogenic and biophysical contributions to increasing atmospheric $\mathrm{CO}_{2}$ growth rate and airborne fraction. Biogeosciences 5, 1601-1613.

Raupach, M. R., Marland, G., Ciais, P., Le Quere, C., Canadell, J. G. and co-authors. 2007. Global and regional drivers of accelerating $\mathrm{CO}_{2}$ emissions. Proc. Natl. Acad. Sci. USA 104, 10288-10293. 
Roe, G. H. and Baker, M. B. 2007. Why is climate sensitivity so unpredictable? Science 318, 629-632.

Schellnhuber, H. J., Cramer, W., Nakicenovic, N., Wigley, T. M. L. and Yohe, G. 2006. Avoiding Dangerous Climate Change. Cambridge University Press, Cambridge, 392 pp.

Schuur, E. A. G., Bockheim, J., Canadell, J. G., Euskirchen, E., Field, C. B. and co-authors. 2008. Vulnerability of permafrost carbon to climate change: implications for the global carbon cycle. BioScience 58, 701-714.

Schuur, E. A. G., Vogel, J. G., Crummer, K. G., Lee, H., Sickman, J. O. and co-authors. 2009. The effect of permafrost thaw on old carbon release and net carbon exchange from tundra. Nature 459, 556-559.

Sitch, S., Huntingford, C., Gedney, N., Levy, P. E., Lomas, M. and co-authors. 2008. Evaluation of the terrestrial carbon cycle, future plant geography and climate-carbon cycle feedbacks using five Dynamic Global Vegetation Models (DGVMs). Global Change Biol. 14, 2015-2039.

Solomon, S., Plattner, G. K., Knutti, R. and Friedlingstein, P. 2009. Irreversible climate change due to carbon dioxide emissions. Proc. Natl. Acad. Sci. USA 106, 1704-1709.

Steffen, W. L., Sanderson, A., Tyson, P. D., Jager, J., Matson, P. A. and co-authors. 2004. Global Change and the Earth System: A Planet Under Pressure. Springer, Berlin, 336 pp.
Stern, D. I. and Kaufmann, R. K. 1996. Estimates of global anthropogenic methane emissions 1860-1993. Chemosphere 33, 159176.

Strassmann, K. M., Plattner, G. K. and Joos, F. 2009. $\mathrm{CO}_{2}$ and non$\mathrm{CO}_{2}$ radiative forcings in climate projections for twenty-first century mitigation scenarios. Clim. Dyn. 33, 737-749.

Tarnocai, C., Canadell, J. G., Schuur, E. A. G., Kuhry, P., Mazhitova, G. and co-authors. 2009. Soil organic carbon pools in the northern circumpolar permafrost region. Glob. Biogeochem. Cycles 23, GB2023, doi:10.1029/2008GB003327.

Trudinger, C. M. and Enting, I. G. 2005. Comparison of formalisms for attributing responsibility for climate change: Non-linearities in the Brazilian proposal approach. Clim. Change 68, 67-99.

Turner, B. L., Kasperson, R. E., Matson, P. A., McCarthy, J. J., Corell, R. W. and co-authors. 2003. A framework for vulnerability analysis in sustainability science. Proc. Natl. Acad. Sci. USA $\mathbf{1 0 0}$, 8074-8079.

Zickfeld, K., Eby, M., Matthews, H. D. and Weaver, A. J. 2009. Setting cumulative emissions targets to reduce the risk of dangerous climate change. Proc. Natl. Acad. Sci. USA 106, 16129-16134.

Zimov, S. A., Schuur, E. A. G. and Chapin, F. S. 2006. Permafrost and the global carbon budget. Science 312, 1612-1613. 